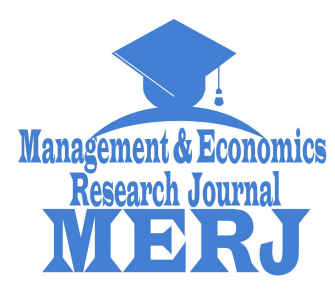

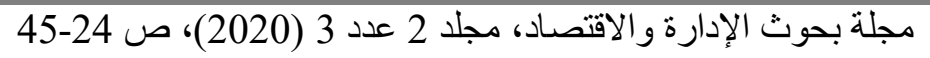

Management \& Economics Research Journal, Vol. 2 No. 3 (2020), pp. 24-45

do) https://doi.org/10.48100/merj.v2i3.108

\title{
أثر صيانة الآلات على تحقيق جودة منتجات المؤسسة الاقتصادية الجزائرية: دراسة حالة مؤسسة مطاحن الحضنة بالمسيلة الحؤية
}

\author{
سمية ديقش \\ 1 طالبة دكتور اه، جامعة فرحات عباس سطيف1 (الجز ائر) \\ $\bowtie$ semia.dekkache@univ-setif.dz
}

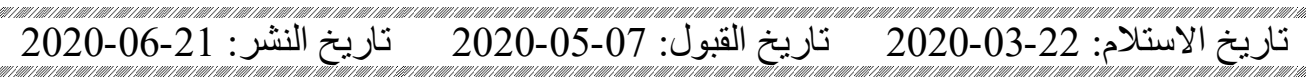

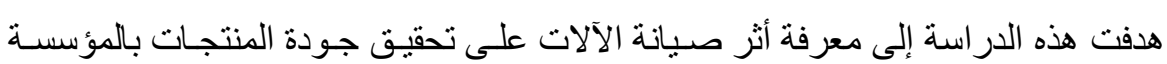

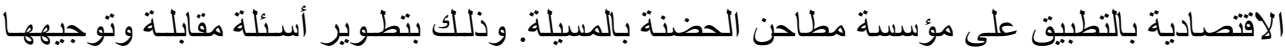

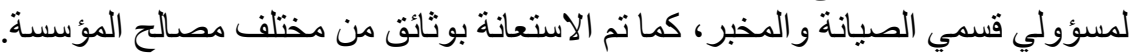

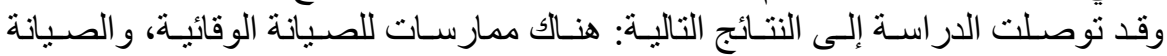

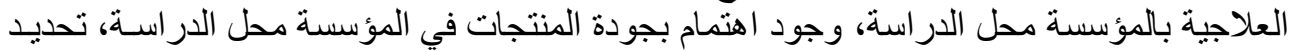

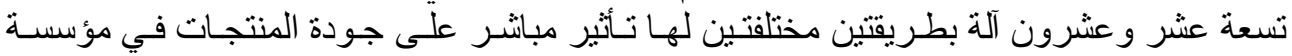
مطاحن الحضنة محل الدماسة. الكلمات المفتاحية: الصيانة، الآلات، جودة المنتجات، مؤسسة مطاحن الحضنة بالمسيلة. تصنيف جال : L22، L11، L15.

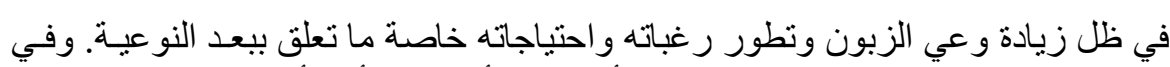

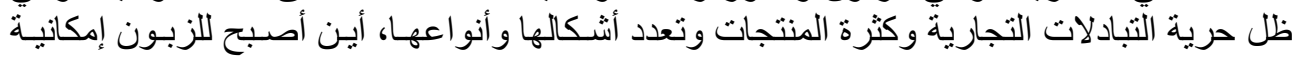

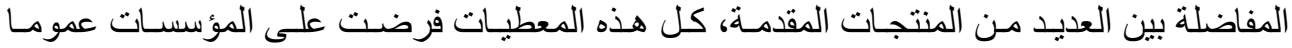

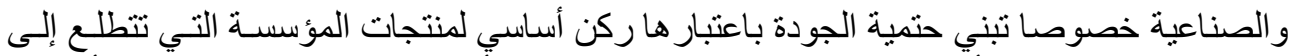

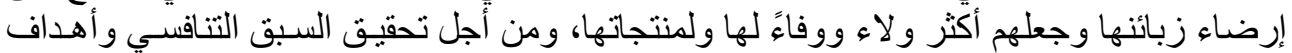

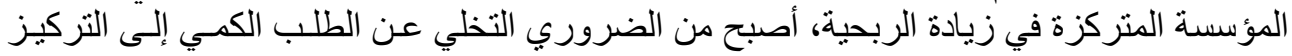

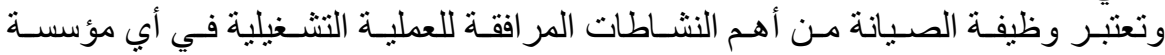

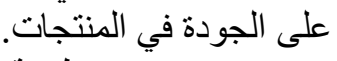

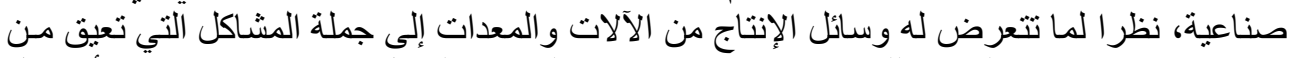

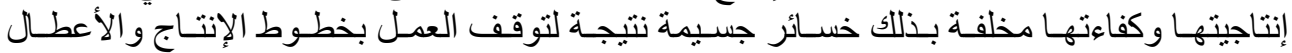

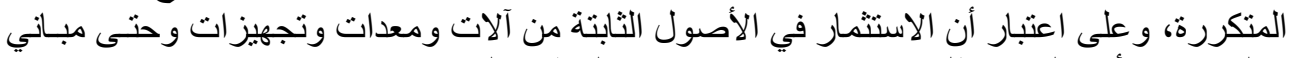

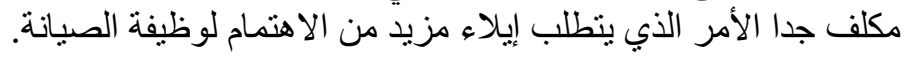




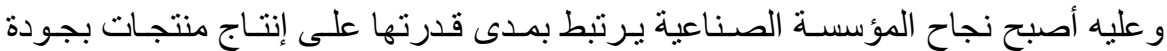

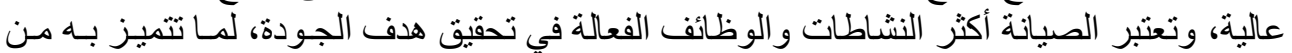

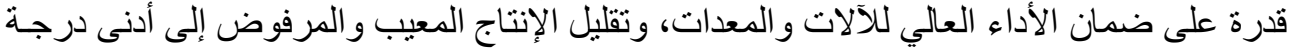
ممكنة.

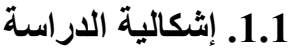

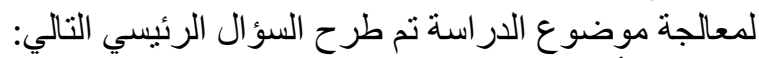

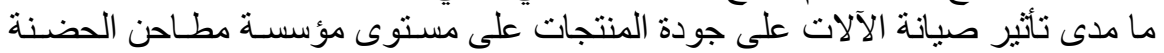

ولمعالجة هذا التساؤل الرئيسي نطرح التساؤلات الفرعية التالية:

بالمسيلة؟

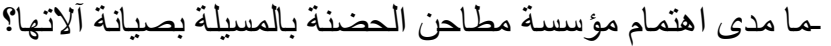

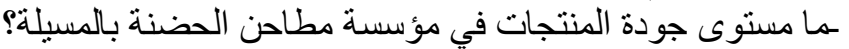

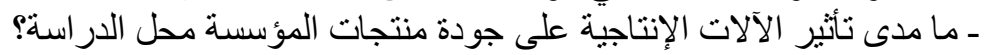

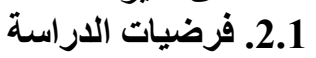

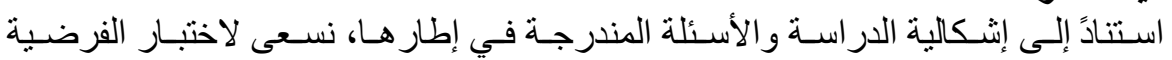

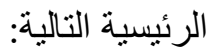

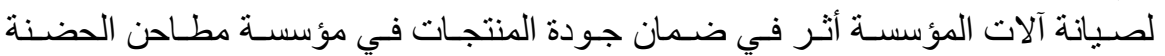

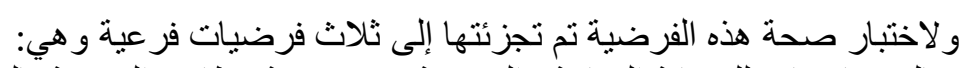

بالمسيلة.

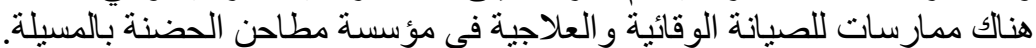

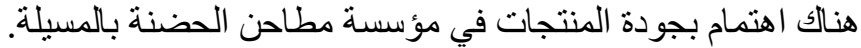

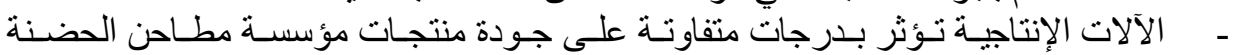

تستمد هذه الدراسة أهميتها من خلال النقاط التالية:

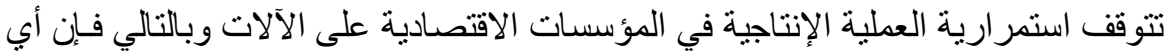

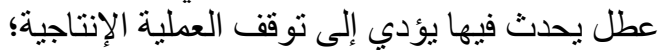

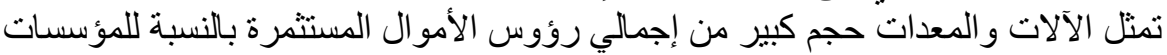

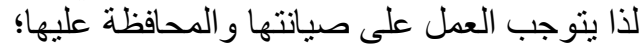

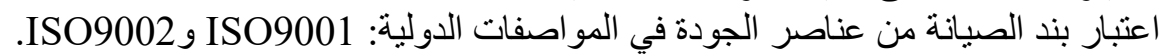

نسعى من خلال هذه الدر اسة بلوغ الألة الأهداف التالية:

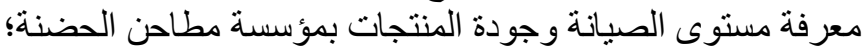

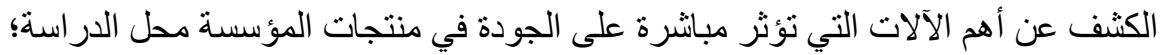

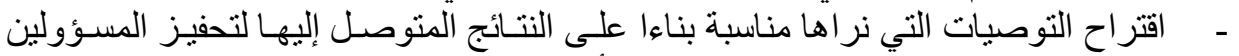
بالمؤسسة في زيادة تفعيل دور الصيانة من أجل ضمان التيان الجودة في منتجاتهم. 5.1

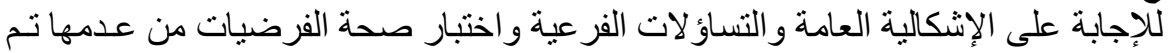

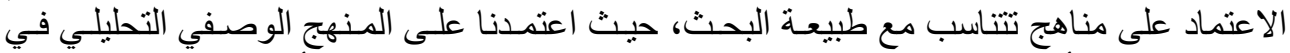

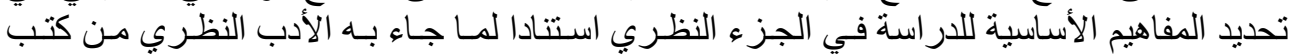

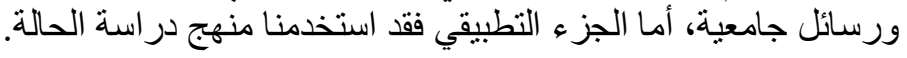


أهم الدر اسات و الأبحاث ذات الصلة المبانثرة بالبحث وفقا لتسلسـلها الزمني على النحو

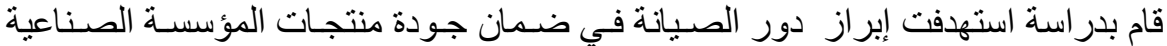

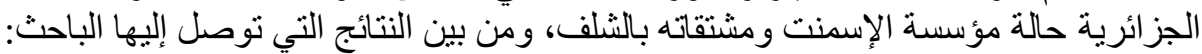

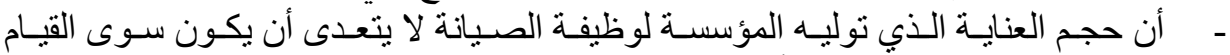

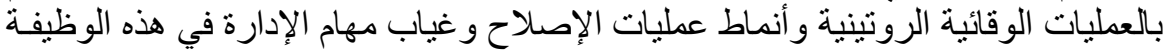

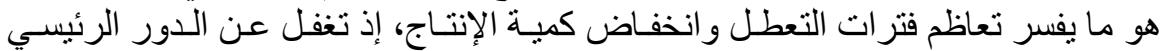

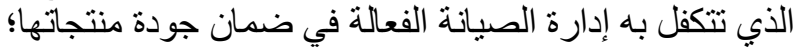

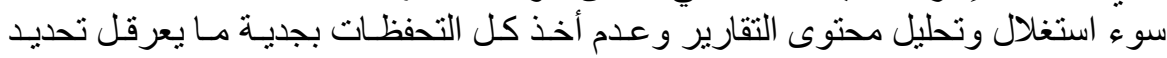

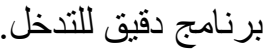

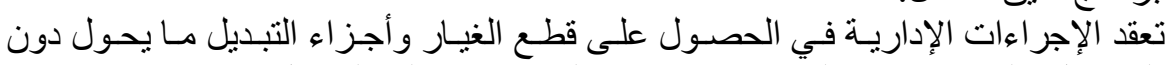

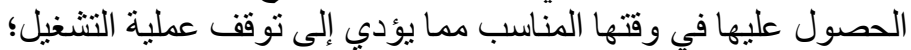

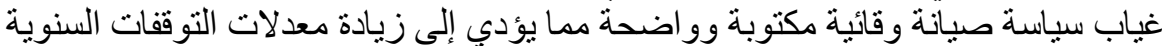
لأسباب يكون بالإمكان تفاديها.

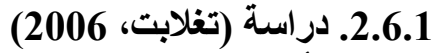

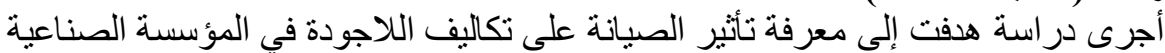

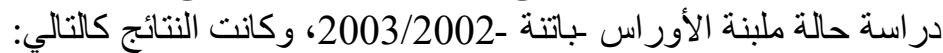

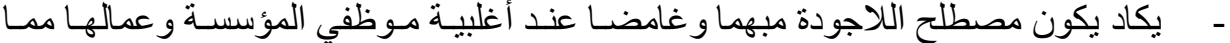

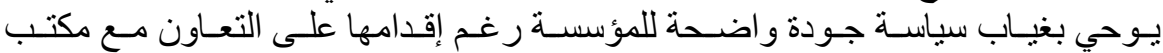

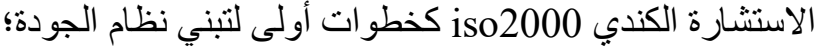

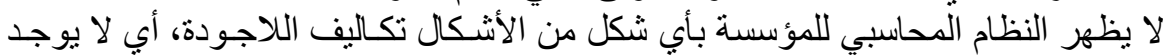

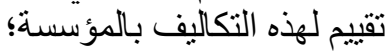
وجود علاقة طردية قوية بين تكاليف اللاجودة و الحجم الساعي لتندخلات الصيانة العلاجية،

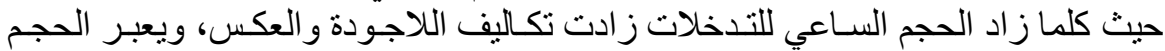

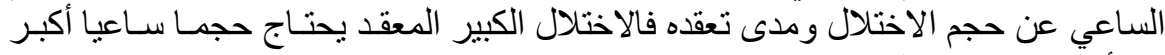
من أجلّ اصلاحه ون و العكس.

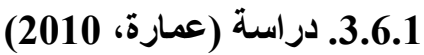

هدفت لمعرفة أثنر الصـيانة على تكساليف الجودة في المؤسسـة الصـنـاعية دراسـة ميدانيـة بمؤسسة MANTAL تلمسان، وتم التوصل إلى:

نقص الاهتمام بالصيانة بمفهومها العلمي و عدم إعطاء الأولوية للصيانة الوقائية واعتبار هـا

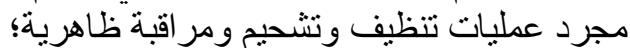

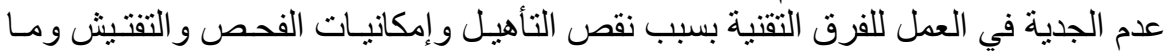
يترتب عنه من نقص في نجاعة التدخلات؛ الاستخدام السيء للتوثيق ون عدم استغلاله لمعرفة فئل أسباب الأعطال المتكررة؛ غياب در اسات دقيقة وتحليل موضو عي الاتي لتكاليف الصيانة.

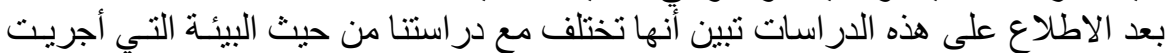

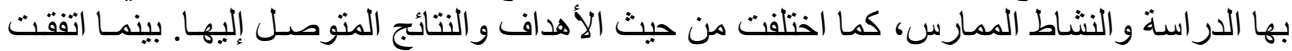
معها في أن معظم المؤسسات عملية التوثيق بها غير فعالة و لا يتم الاستفادة منها. 


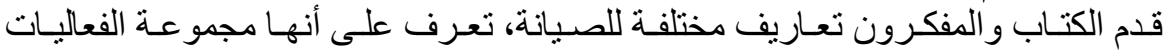

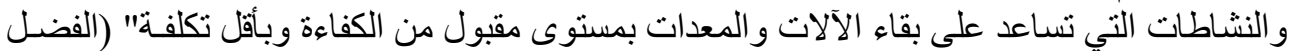

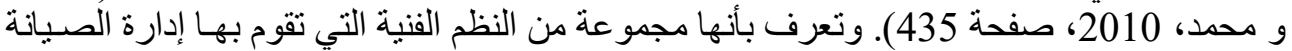

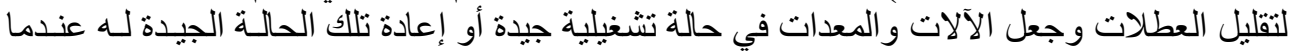

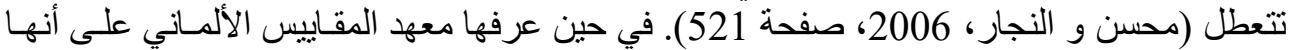

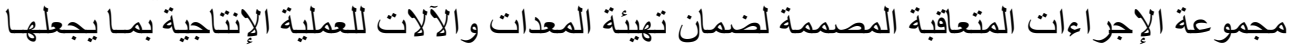

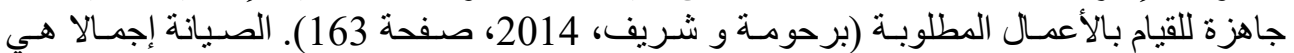

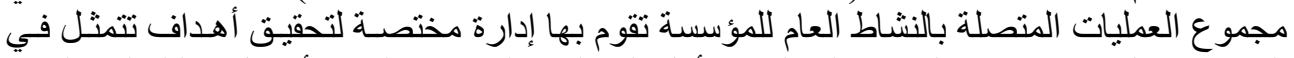

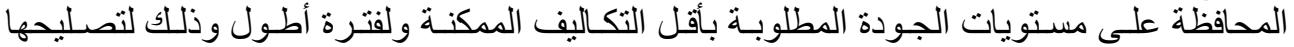

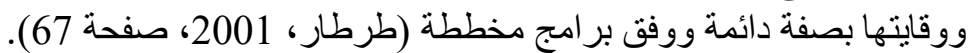

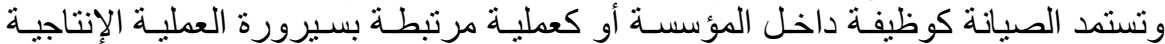

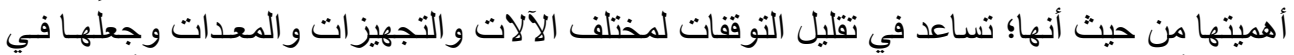

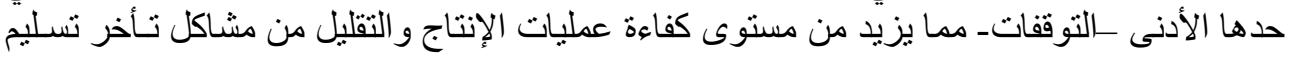

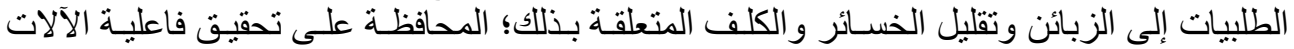

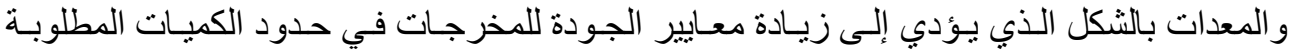

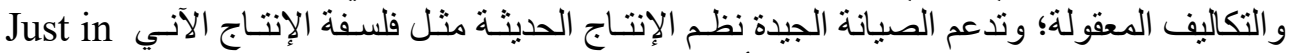

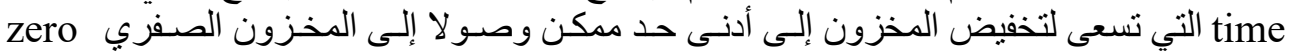
inventory

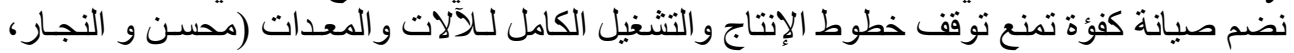

2006، الصفحات 522-523 (523).

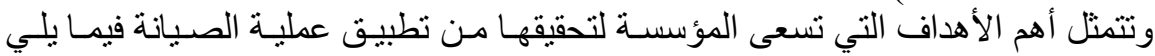

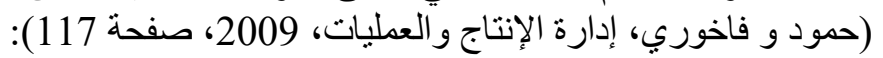

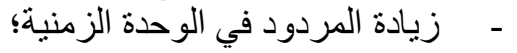

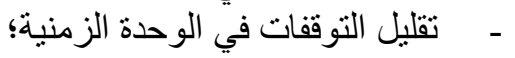

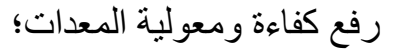
تعظيم ميسورية الآلات و المعدات العات للإنتاج؛

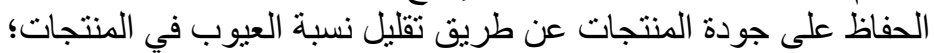

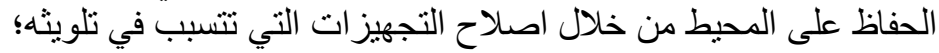

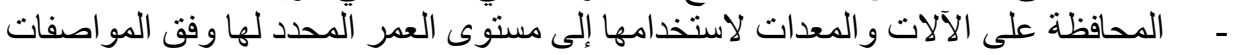

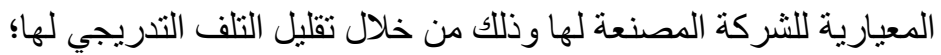
ضمان سلامة العاملين الذين يستخدمون هذه المعدات.

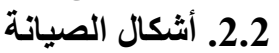
تشير معظم أدبيات الدراسة إلى وجود نو نوعين أو شكلين رئيسين للصيانة هما:

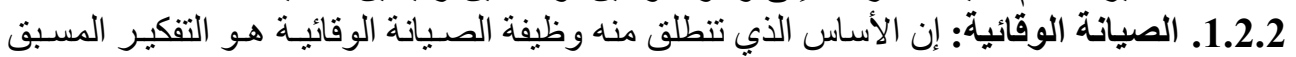

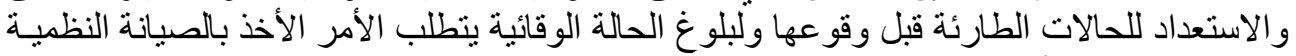

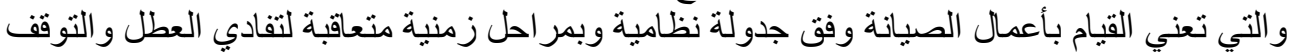

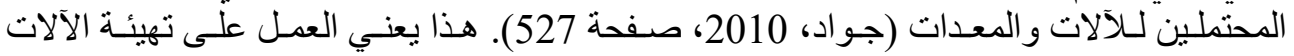

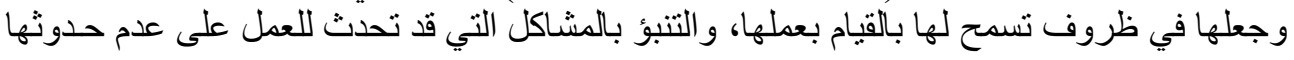


أو على الأقل تقليلها وهو مـا يجنبهـا مشـاكل كبيرة مثنل تفـاقم تكـاليف الصبيانة أو الاضطر ار إلى

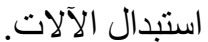

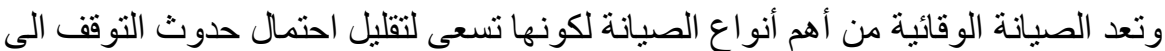

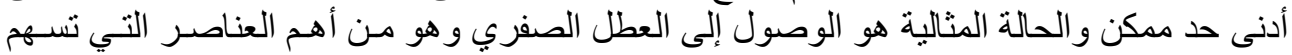

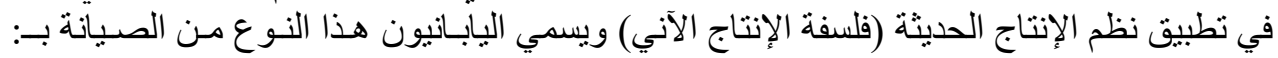
Just in time maintenance

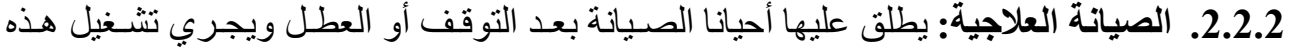

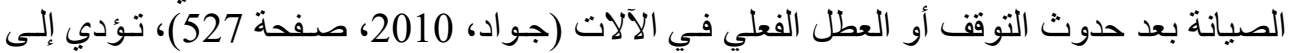

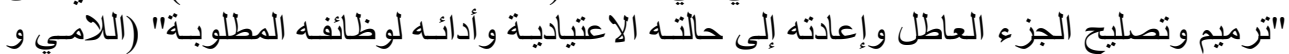

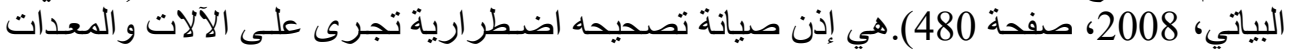

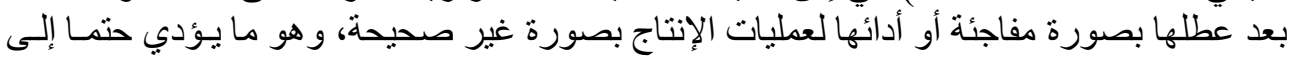

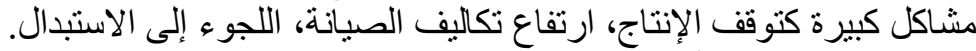

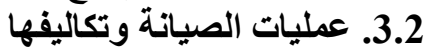
حتى تتضح الرؤية أكثر عن وظيفة الصيانة وائة وجب التطرق للعمليـات و الخطوات الميدانيـة لمختلف أعمال الصيانة ثم تكاليفها. 1.3.2. 1.3.2

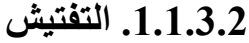

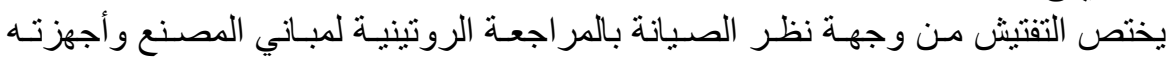

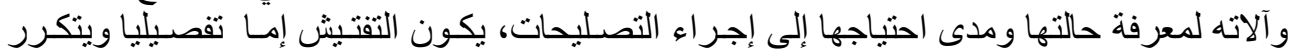

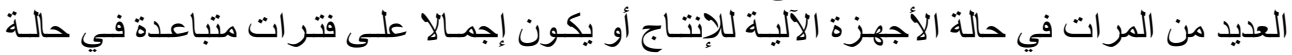

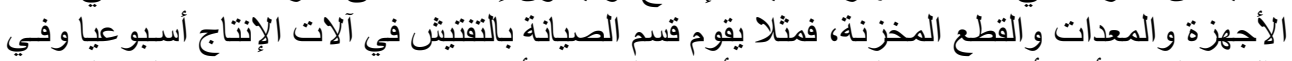

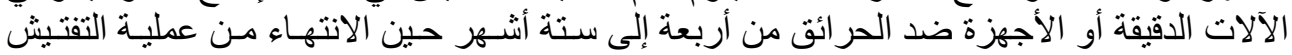

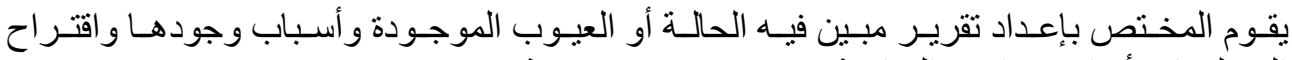

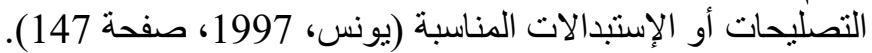

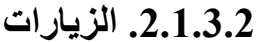

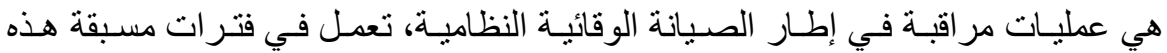

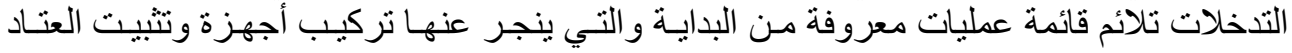

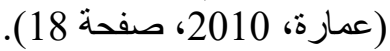
3.1.3.2.

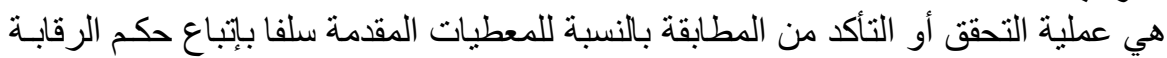

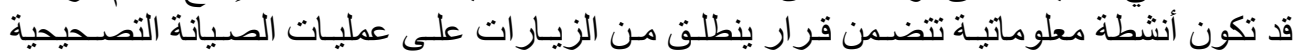
(عمارة، 2010، صفحة 18 18). 2.3.2 تندر ج تحت الصيانة العلاجية العمليات والخطوات الميداتية النية التالية:

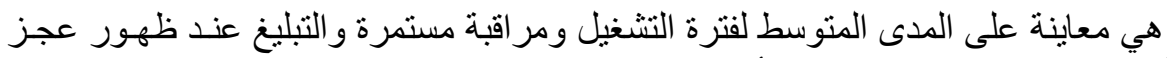

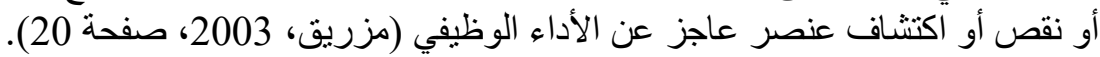

2.2.3.2 التعيين أن التين

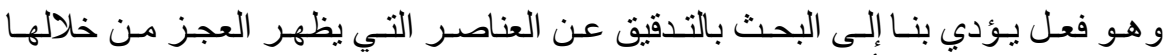
(مزريق، 2003، صفحة 20). أي تحديد العناصر التي تؤدي الى حدوث الخئ الخلل و العطب. 


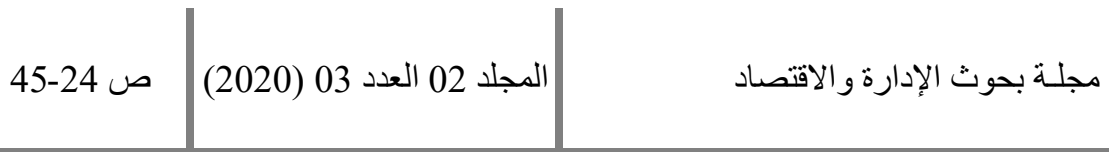

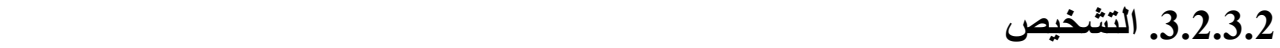

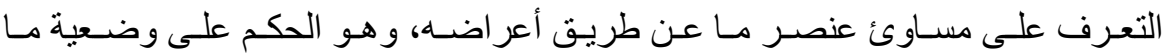

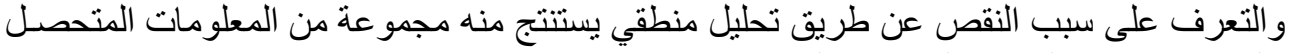

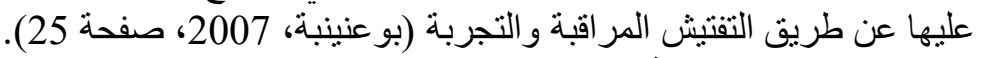

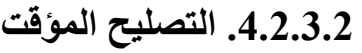

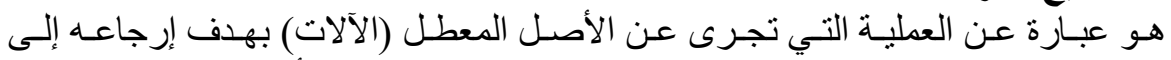

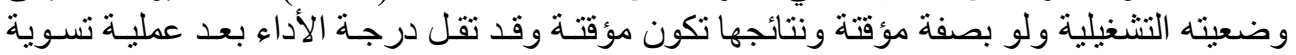

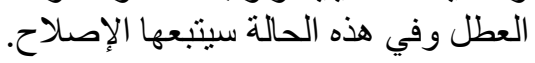

3.2.3.2

تذخل نهائي ومحدود للصيانة الإصلاحية بعد العطل أو الخلل، فعملية الإصلاح هي عمليـة

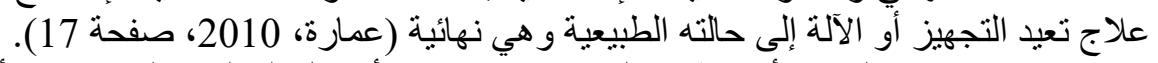

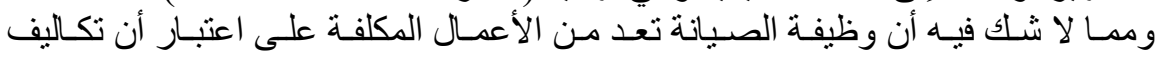

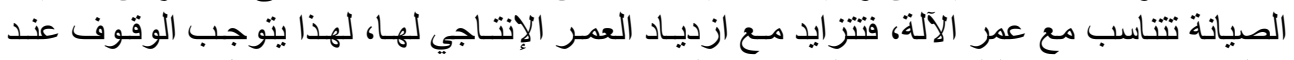

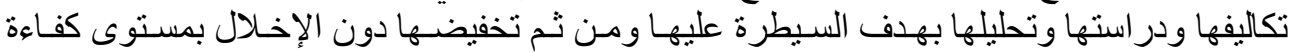

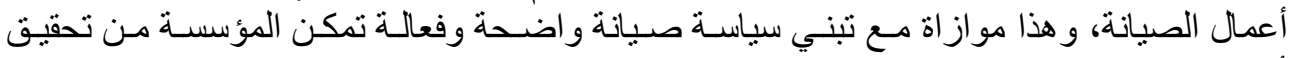
أهدافها المرجوة من عملية الصيانة. إنّ العلاقة بين تكاليف الصيانة الوقائية والصيانة العلاجية يمكن أن تظهر من خلال الثـكل شكل رقم (01): العلاقة بين تكاليف الصيانة الوقائية وتكاليف الصيانة الإصلاحية.

التاللي:

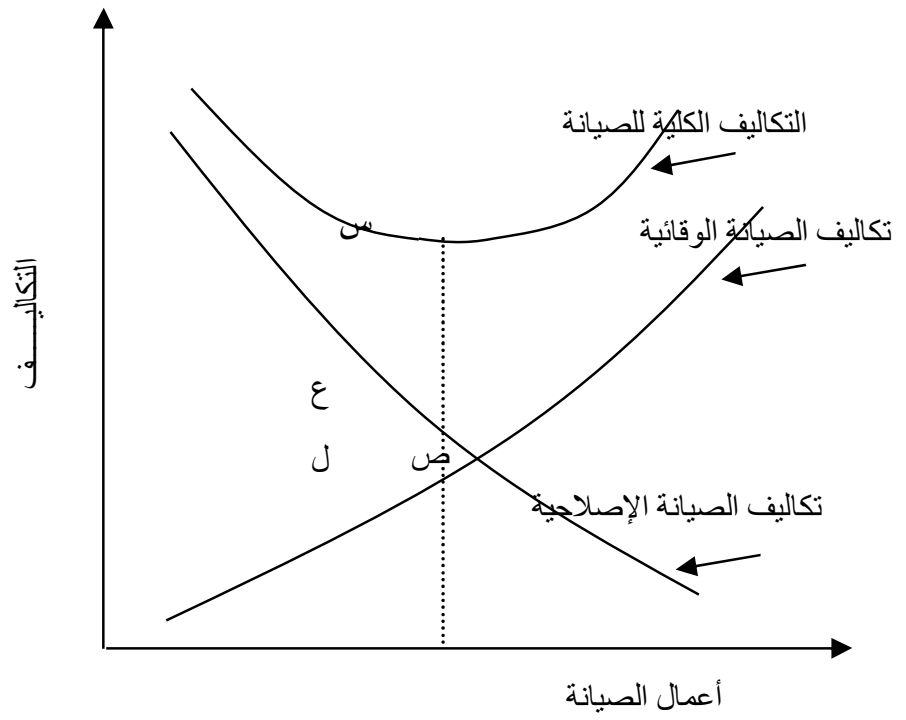

المصدر : (حسن، 1998، صفحة 126).

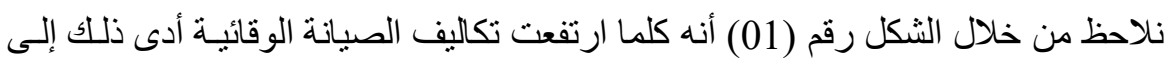

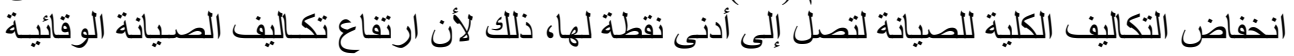

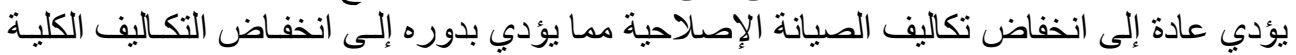


للصيانة، و الهدف دائما هو التوصل إلى النقطـة التي تؤدي إلىى انخفـاض تكـاليف الصيانة الوقائيـة و الإصلاحية إلى أقل حد مدكن.

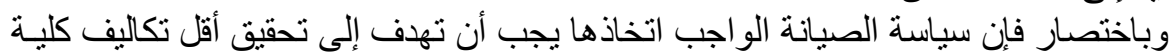

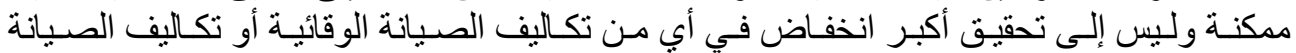
الإصلاحية (حسن، 1998، صفحة 127).

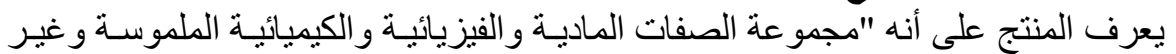

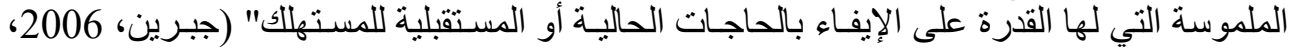

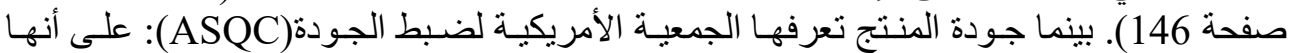

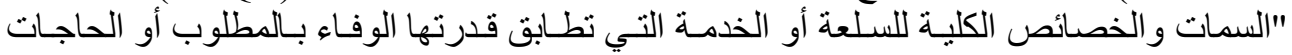

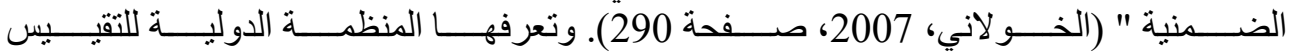

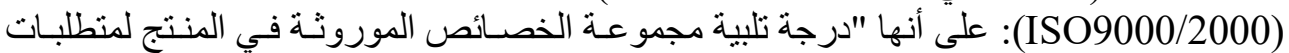

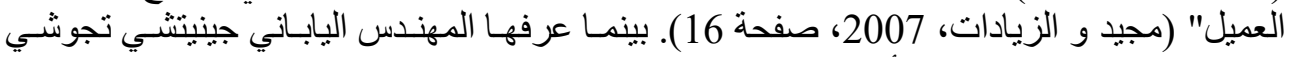
(genichi Taguchi)

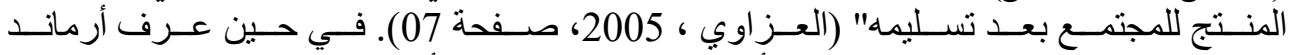

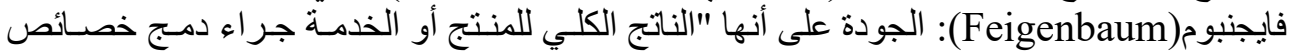

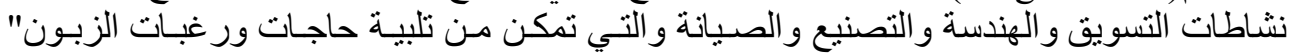

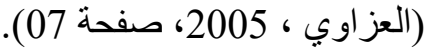
ويمتلك المنتوج أبعادا متعددة مرتبطة بالجودة وتحقبقها يؤدي إلى تلبيـة منطلبـات الزبائن

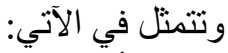

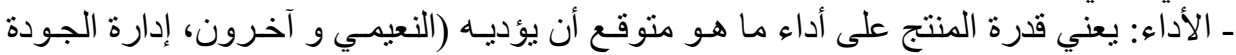

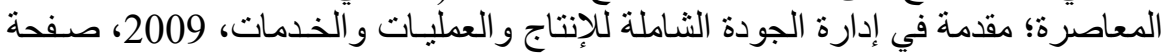

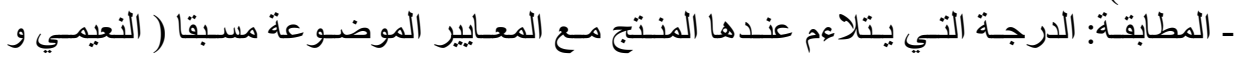

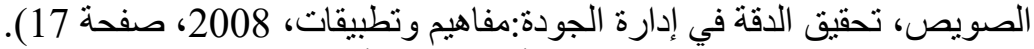

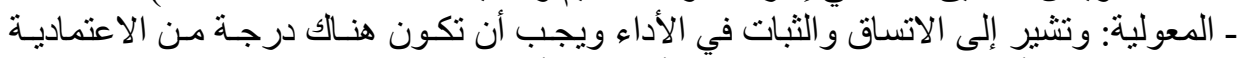

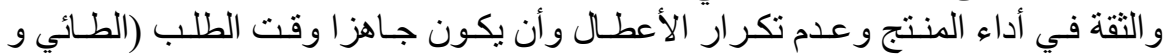

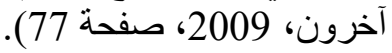
ـ الجمالية: و هي تعكس المظهر الخارجي للمنتج و الخصائص المفضلة للأفر اد حول هذا المنتج

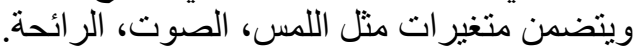

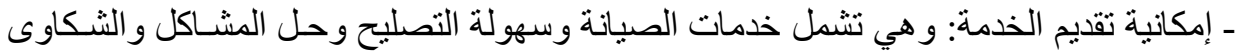

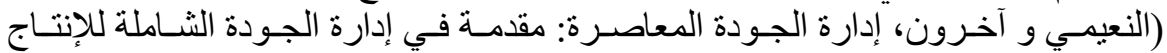

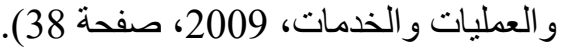

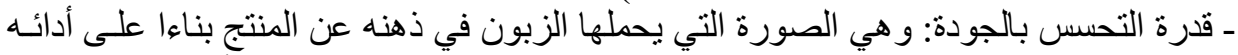

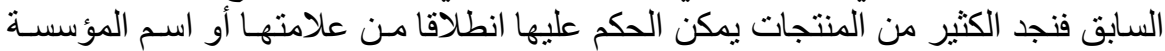
المصنعة أو المقدمة لها. ـ مدة الصلاحية: و هي مدة استخدام المنتج قبل ضعف أدائه وفقدانه خصائصده أي قبل استهلاكه. 
و هناك أربعة محددات أساسية للجودة تساعد المنتجات أو الخدمات على تحقيق الغرض

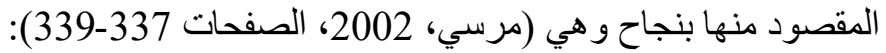

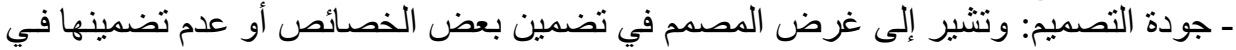

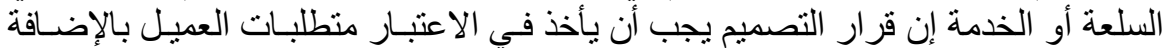

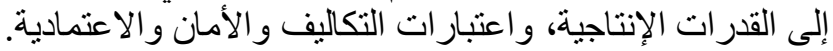

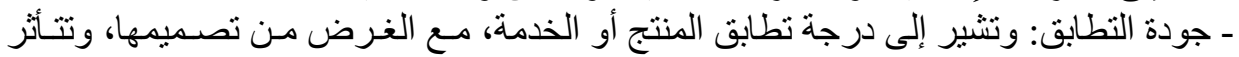

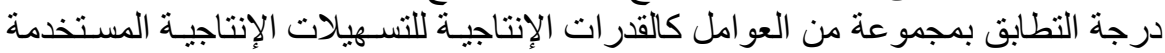

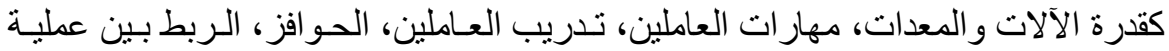

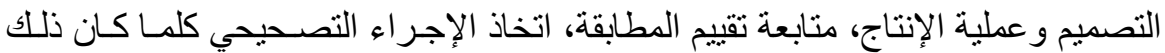

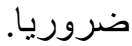

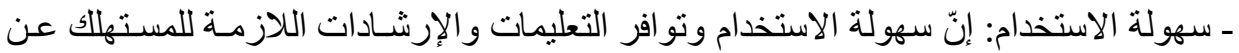

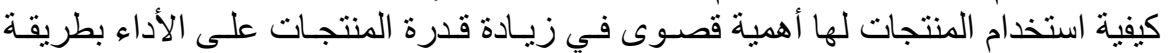

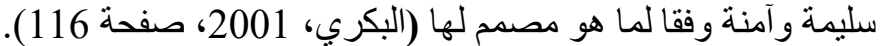

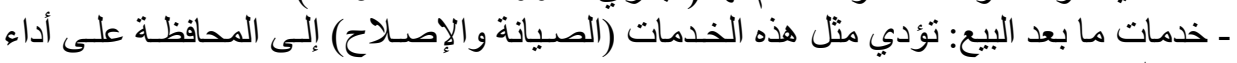

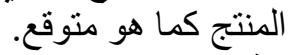

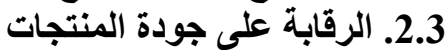

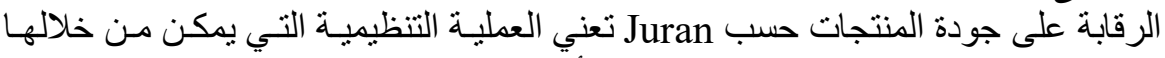

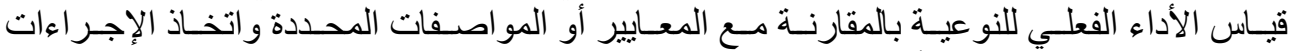

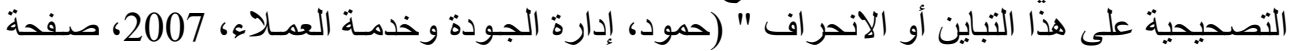

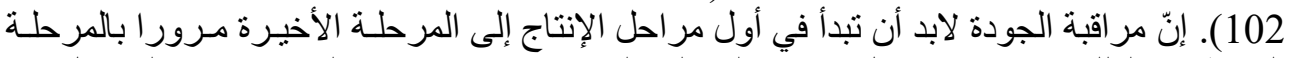

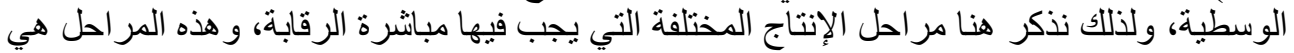

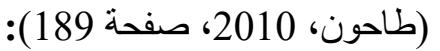

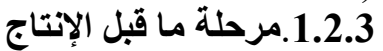

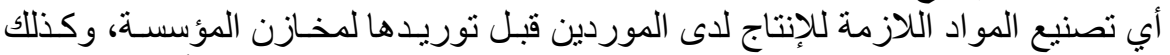

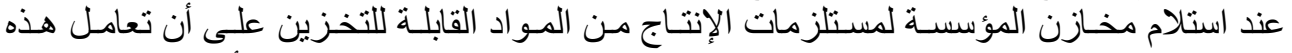

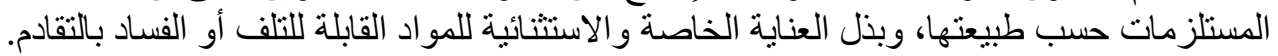

و هذه المرحلة تغطي مر احل الإنتاج منذ بدء الإنتاج في المرحلة الأولى حتى نهاية المرحلة

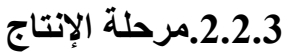

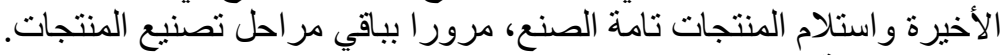

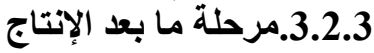

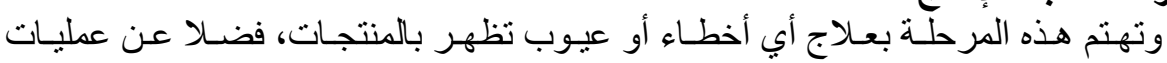
التغطية و الضمان لها، وكذلك متابعة المنتجات لإى التى العملاء.

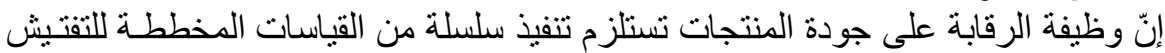

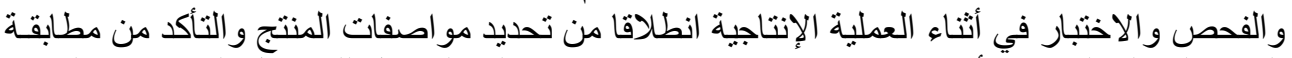

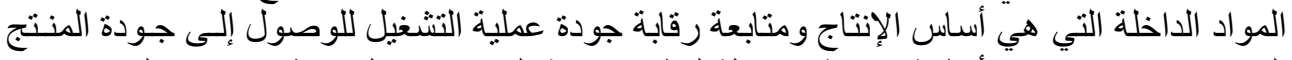

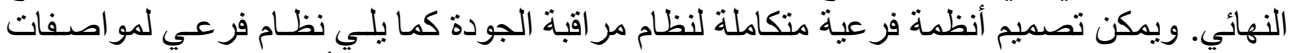

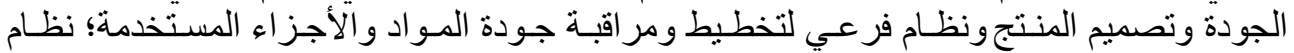

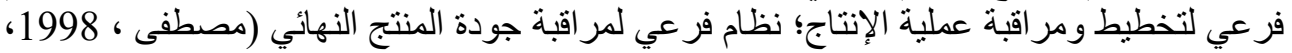




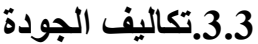

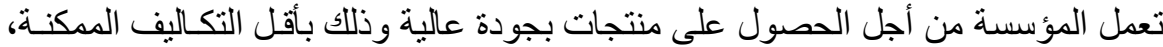

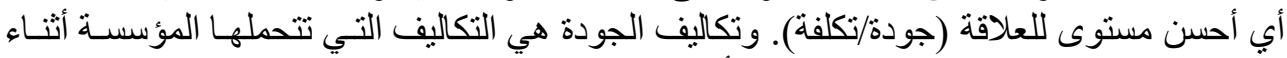

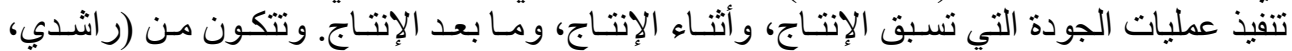

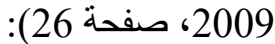
ـ تكاليف اللاجودة: وهي عبارة عن النفقات الناتجة عن الأخطاء و الضياع مما يؤدي إلى ضياع

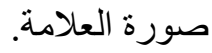
ـ تكاليف الجودة: وهي عبارة عن نفقات الاستثمار من أجل التقليل من تكاليف اللاجودة بغرض تعظيم الإنتاجية.

$$
\text { وتصنف عناصر تكاليف الجودة إلى أربع عناصر أساسية: }
$$

1.3.3.3.3.3

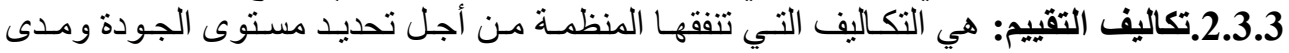
مطابقتها للمو اصفات المحددة. و وبلتكاليف الفشل الداخلي: هي التكاليف التي يتسبب فيها حدوث أخطساء وعيوب في الإنتاج وقبل وصول المنتجات المعيبة إلى السوق.

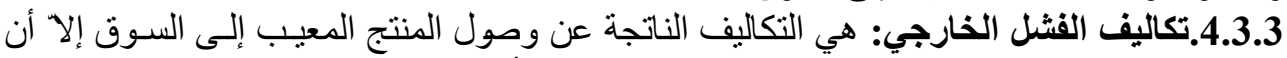

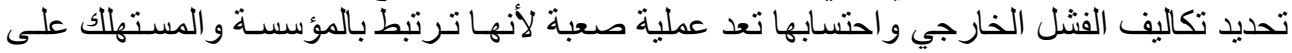
حد سواء. إذن التكاليف الكلية للجودة تتمثل في مجموع تكاليف الوقاية، تكاليف التقييم، تكساليف الفثل الداخلي، وتكاليف الفشل الخارجي، كما يوضح الثكل التنالي:

$$
\text { شكل رقم (02): التكاليف الكلية لمر اقبة الجودة }
$$

التكاليف

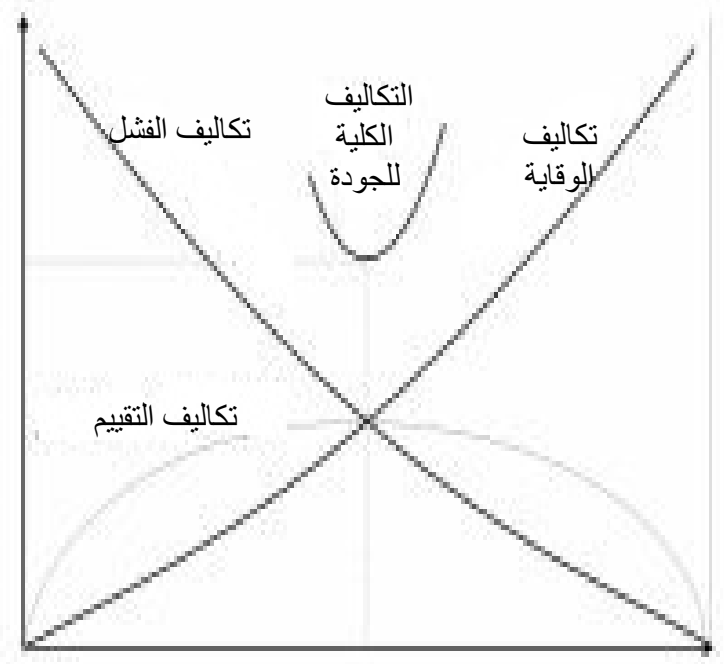

100\% معيب 0

مستوى الجودة الأمنل

\% 0 معيب

المصدر : (ر اشدي ، 2009، صفحة 28). 


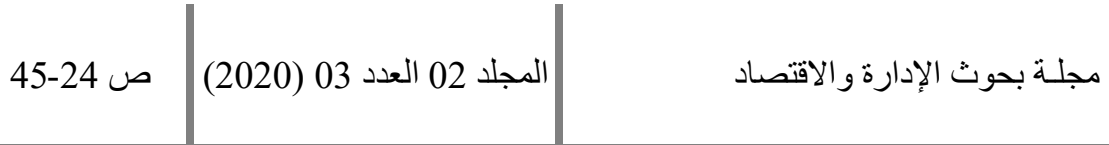

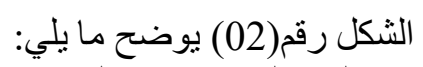

- زيادة تكاليف الوقاية يؤدي إلى زئادة مستوى الجودة إلى إلى أن يصل إلى نسبة (0\%معيب) أي

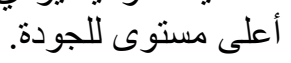

- زيادة تكاليف الفثل يؤدي إلى انخفاض مستوى الجودة إلى أن يصل الى نسبة (100\%معيب)

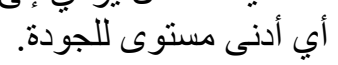

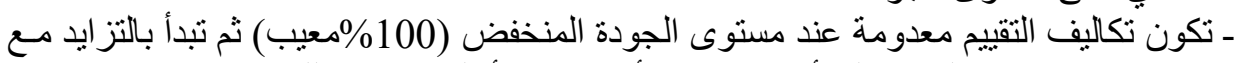

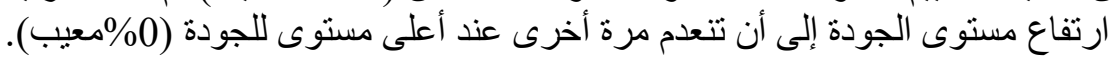

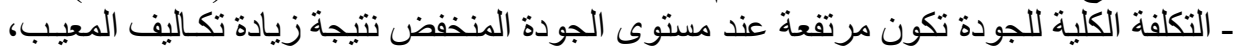

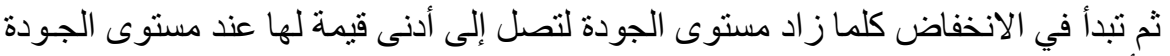

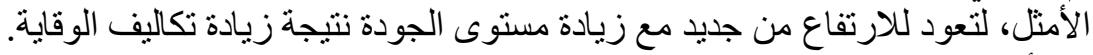

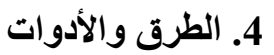

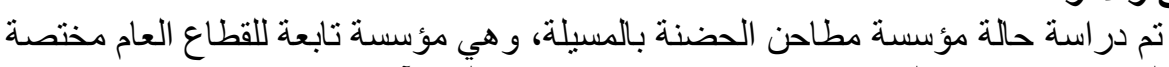

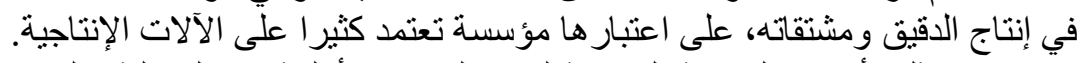

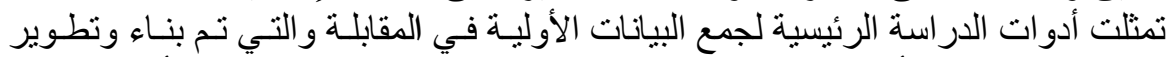

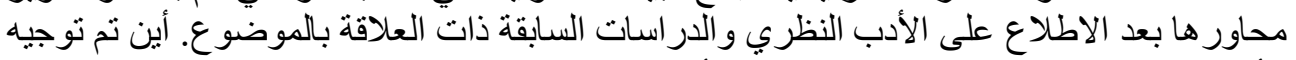

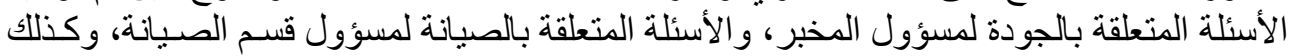

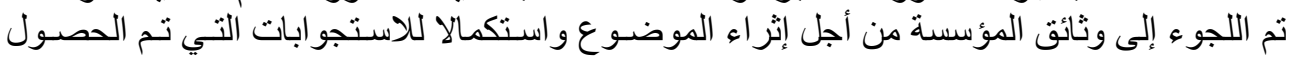

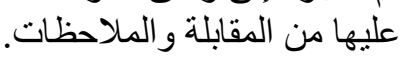
وتم قياس أثر المتغير المستقل الصيانة على المتغير التابع جودة المنتجات باستخدام مؤشـر

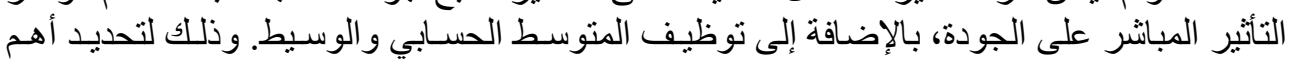

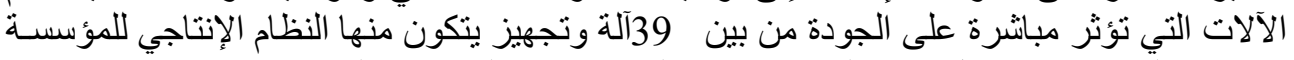

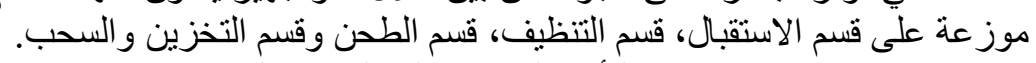
ويتم حساب مؤشر الثأثير المبانشر على الجودة بالعلاقة: (عمارة، 2010، صفحة 152)

\section{$\mathrm{IDSQ}=\mathrm{IQ} \times \mathrm{IM} \times \mathrm{IS}$}

$$
\begin{aligned}
& \text { IQ التأثير على الجودة : IQ } \\
& \text { : نأثير الصيانير علئة : IM }
\end{aligned}
$$

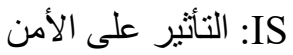

$$
\begin{aligned}
& \text { مؤشر التأثير المباثر على الجودة : IDSQ }
\end{aligned}
$$

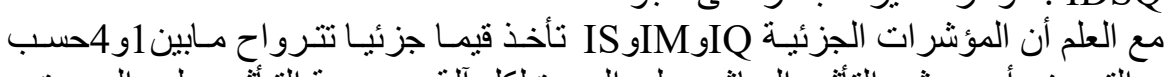

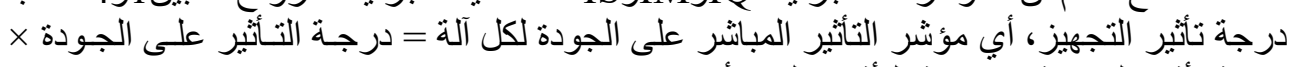

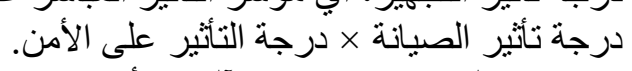

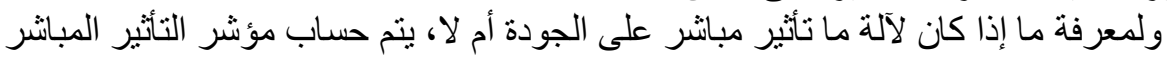

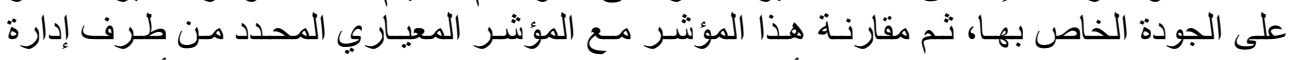

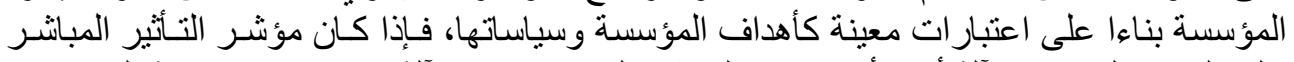

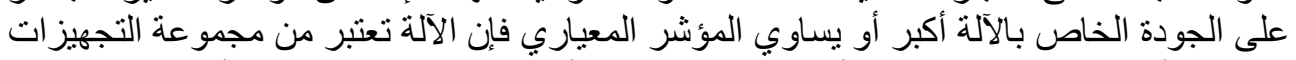

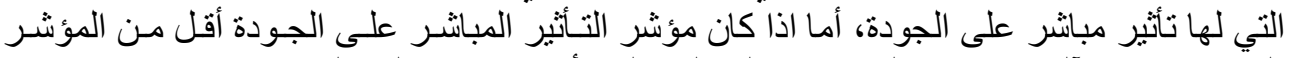

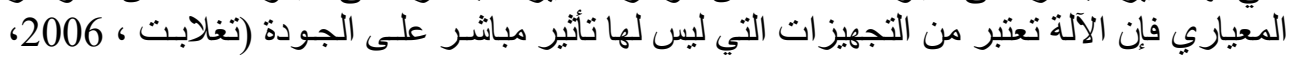

صفحة 84) 


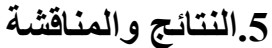

1.5. النتائج المتعلقة بمدى الهتمام مؤسسة مطاحن الحضنة بالمسيلة بصيانة آلاتها.

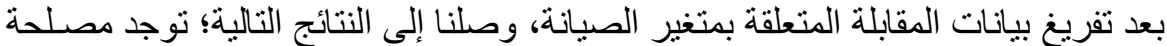

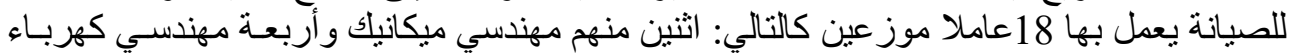

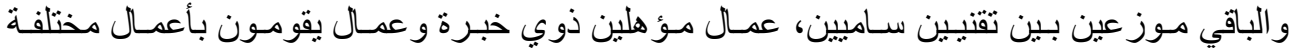

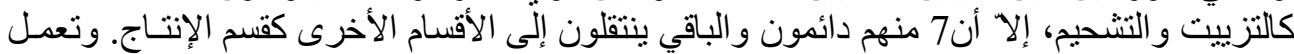
مصلحة الصيانة وفق الهيكل التنظيمي التالي:

شكل رقم (03): الهيكل التنظيمي لمصلحة الصيانة

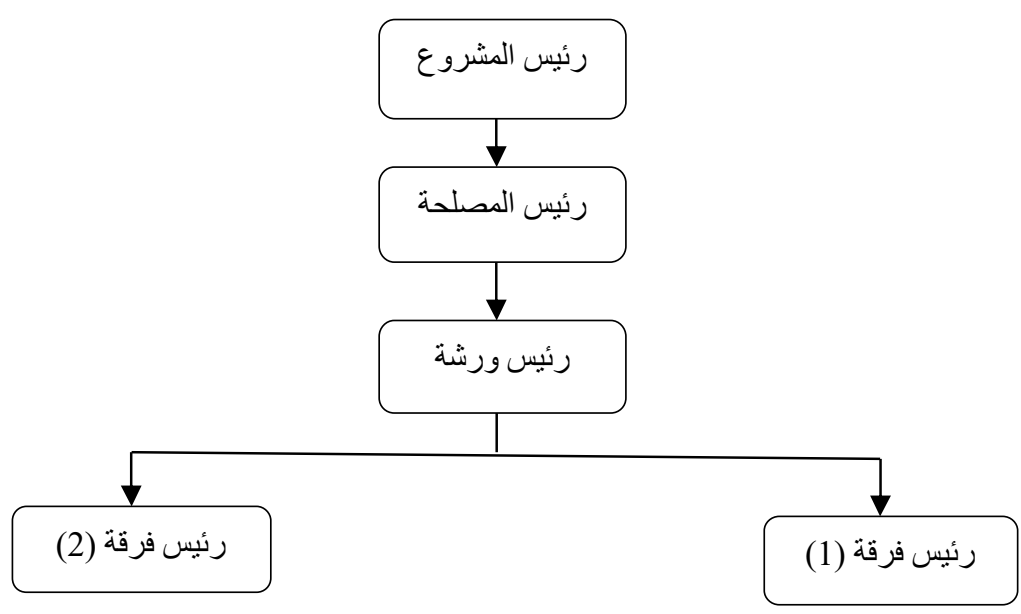

المصدر : (مؤسسة مطاحن الحضنة، 2015).

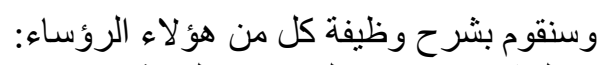

- رئيس المشروع: يقوم بالدر اسات التقنية وتركيب الأجهزة في حالـة تجهيز التهية أو استبدال بعض الآلات بمساعدة عمال الصيانة.

- رئيس المصلحة: يقوم بالتنسيق مـع رئيس المشـروع مـن أجل وضـع الخطط اللازمـة لعمل

$$
\text { الصيانة. }
$$

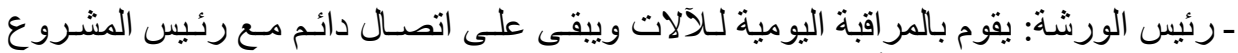

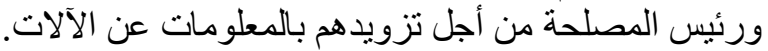

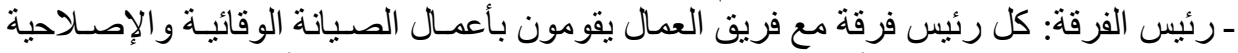

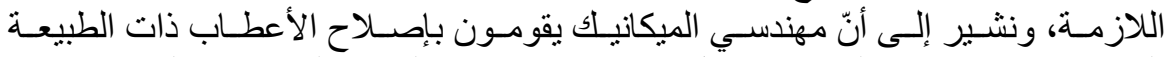

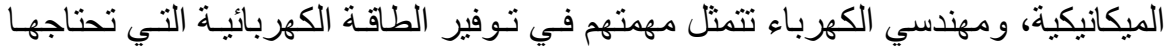

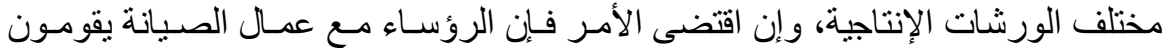

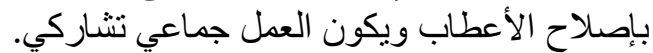

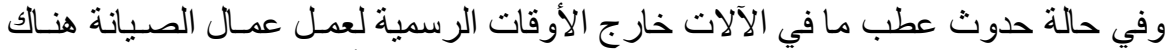

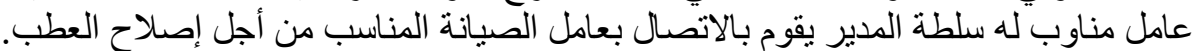

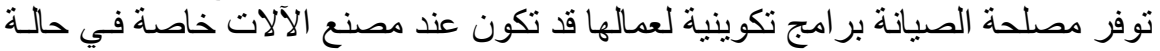

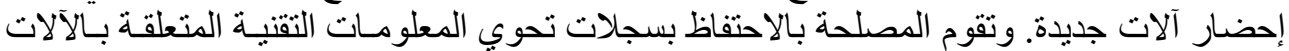


المجلد 02 العدد 03 (2020) ص 24-45

وكذلك تسجيل الأعطل التي عرفتها الآلات و أعمال الصيانة التي خضعت لها و هـي تعتمد في ذلك إلك

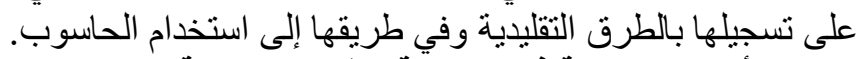

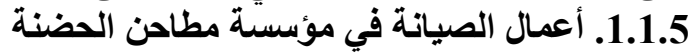

تعتمد مؤسسة مطاحن الحضينة للحفاظ على سونى سلامة آلاتها وتجهيز اتها على الصيانة بنو عيها

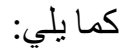
1.1.1.5

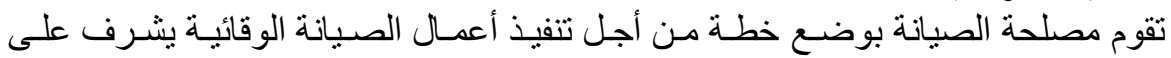

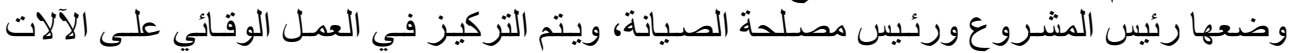

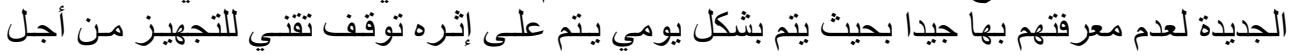

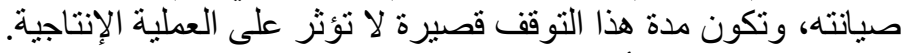

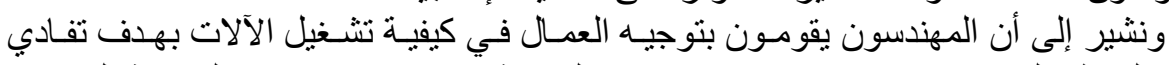

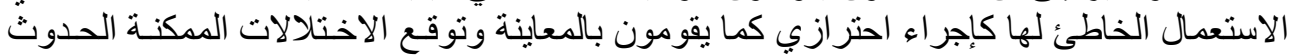

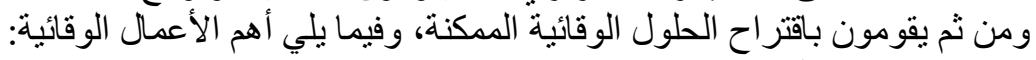
- - ت تنظيف المصفاة؛ - - تغيير بعض قطع الغيار (حسب مدة الصلاحية)؛

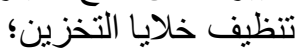
تنظيف خلايا الر احة؛

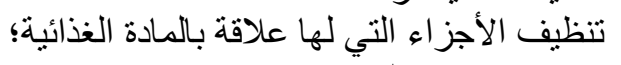

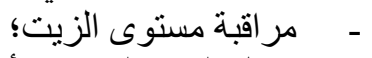

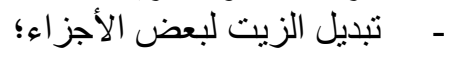

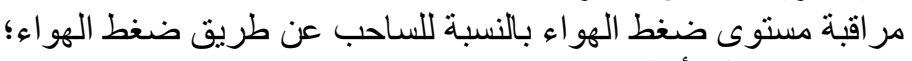

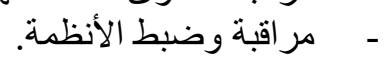

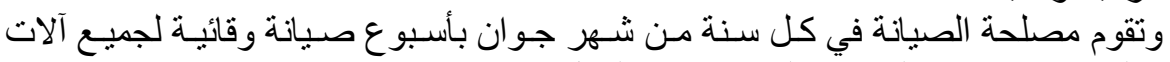
وتجهيزات المطحنة تتوقف على إثره المطحنة عن العمل. 2.1.1.5

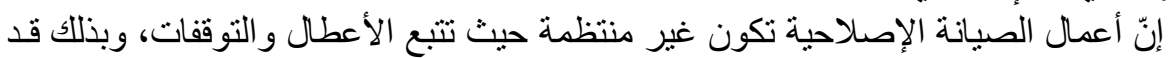

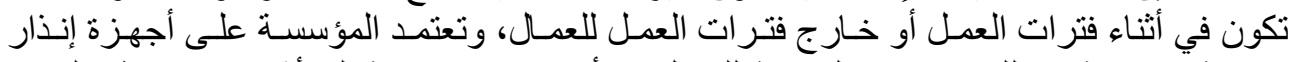

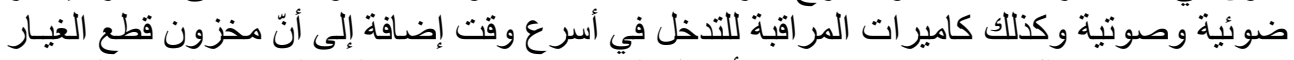

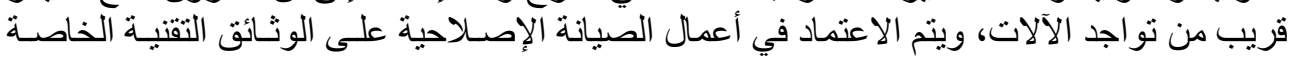

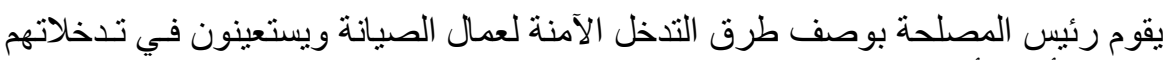
بالآلات.

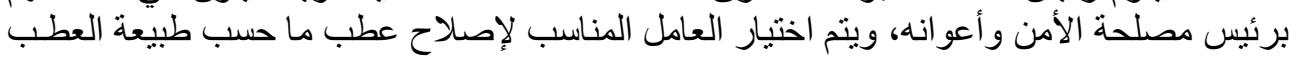

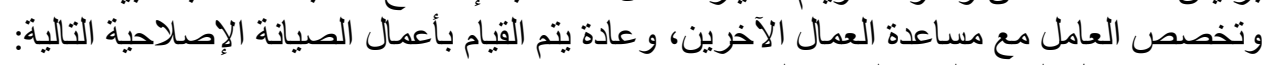
- - تعديل الجزء المتحرك من المحركات؛ - - تصنيع بعض المسننات؛ -

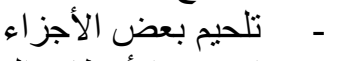
- - إصلاح الأعطاب المختلفة للآلات؛ 


$$
\text { - } \text { - }
$$

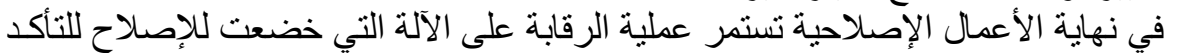

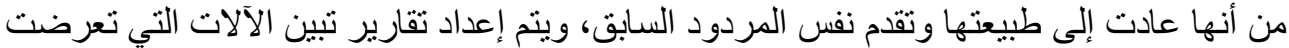

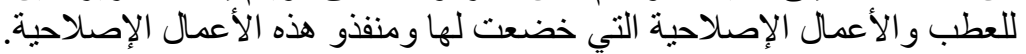

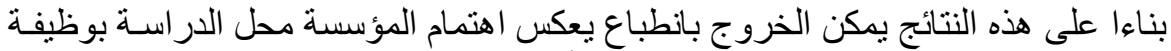

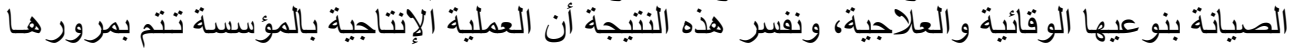

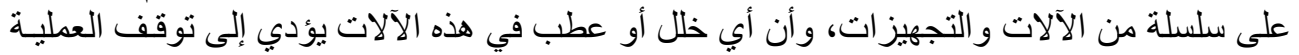

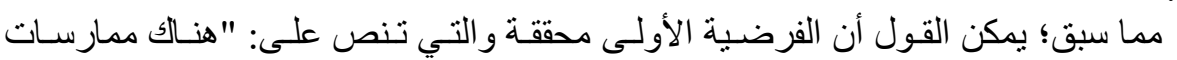

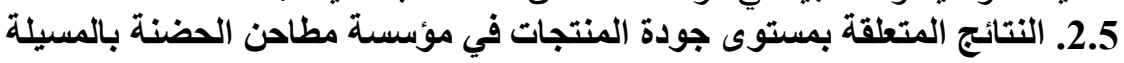

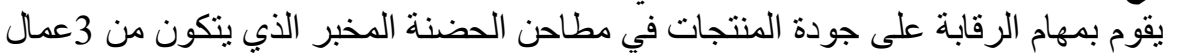

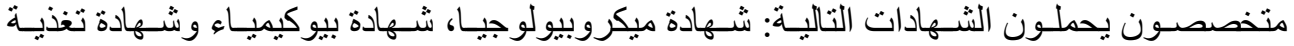
وتغذب. وبعمل المخبر وفق الهيكل التنظيمي التالي:

شكل رقم (04): الهيكل التنظيمي للمخبر

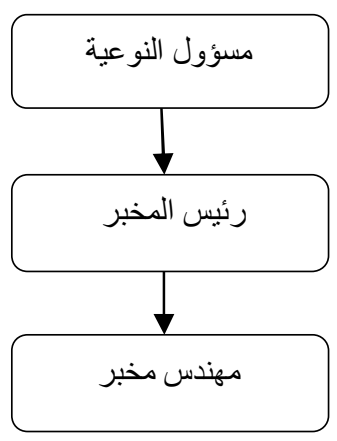

المصدر: (مؤسسة مطاحن الحضنة، 2015).

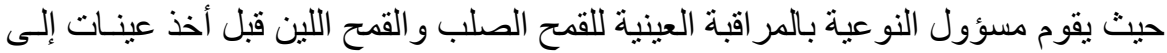

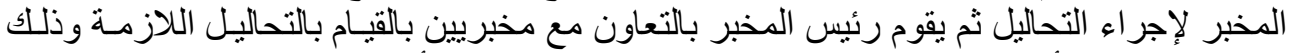

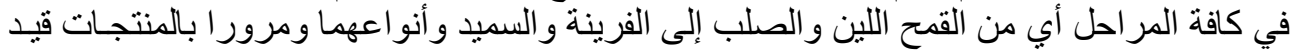
التنفيذ. يوفر المخبر بر امج تكوينية لعماله عن طريتق حضـور مختصـين إلى المخبر خاصسة في

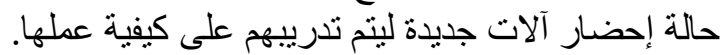
قبل دخول المادة الأولية إلى المؤسسة تقوم هذية عذه الأخيرة بتوصيف المادة الأولية المطلوبة

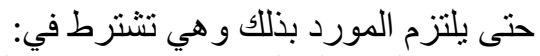

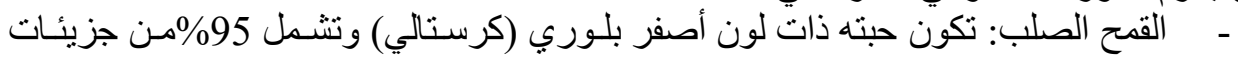
السميد و5\%من الغلاف الخارجي. 


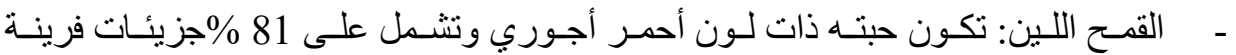
و5\% غلاف خارجي و14\% بنين.

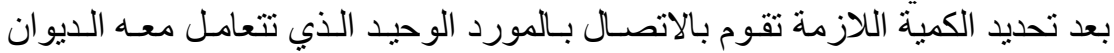

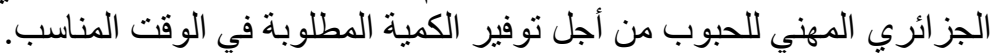

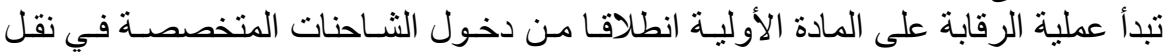

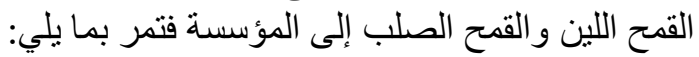

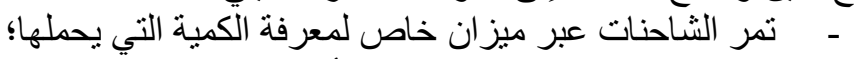

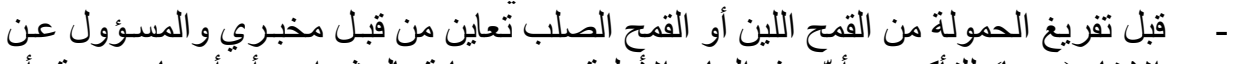

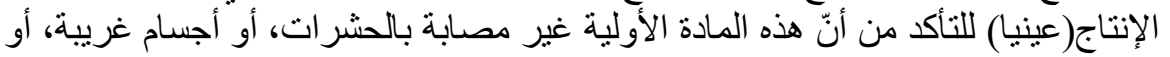
مرض مال. إذا ثبت أن هذا القمح لا بعاني من المشاكل السابقة، توجه الثاحنات إلى تفريغ الحمولة في

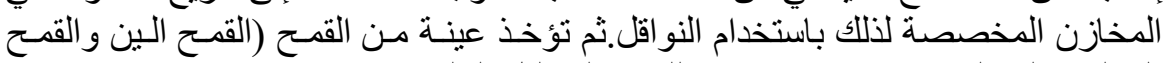
الصلب) إلى المخبر عادة تكون 1كغ للقيام بالتحاليل التالية:

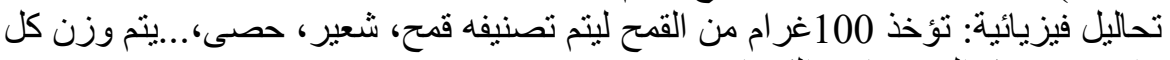
واحدة من هذه التصنيفات (الكميات).

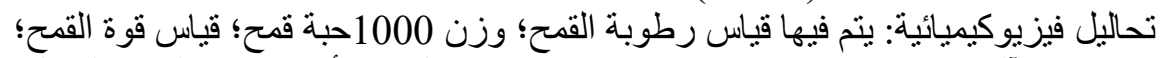

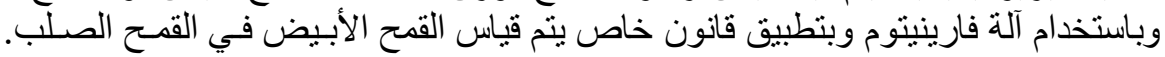

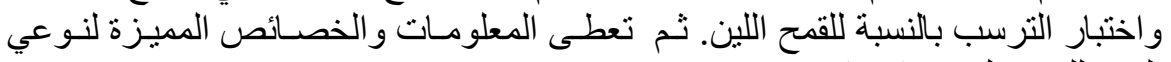

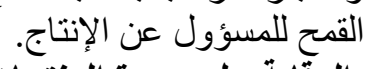

\subsubsection{5 الرقابة على جودة المنتجات قيد الإنتاج التنفيذ}

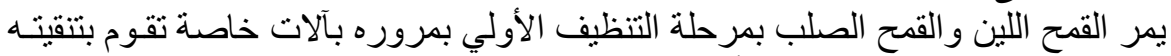

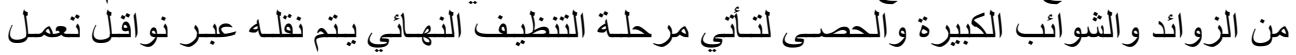

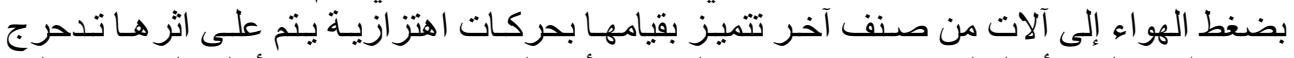

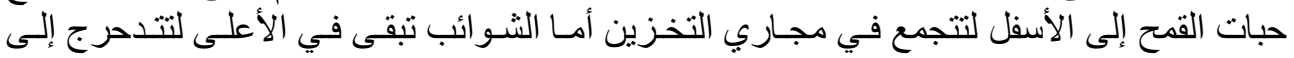
حاوية خاصنة بها.

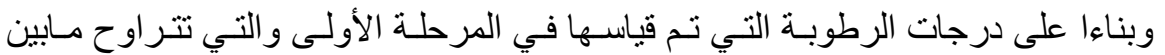

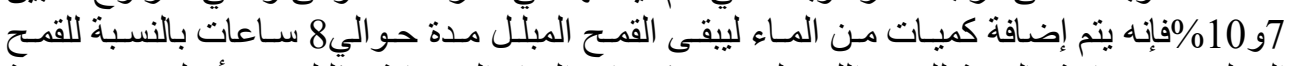

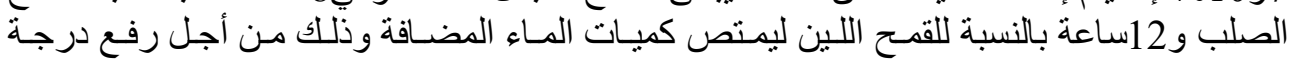

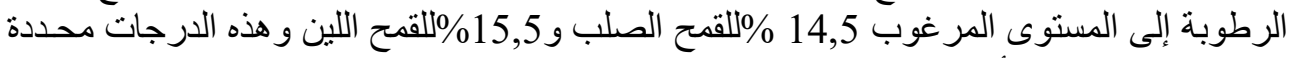

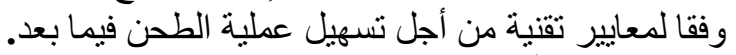

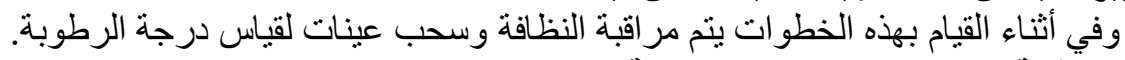

3.1.2.5 الرقابة على جودة المنتجات النهائية

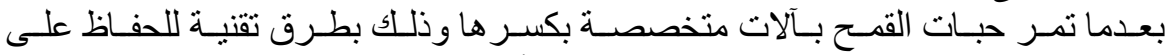

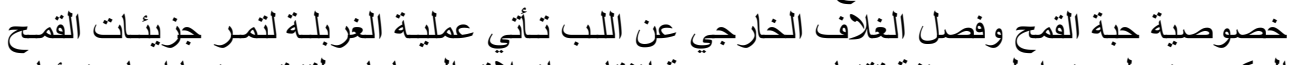

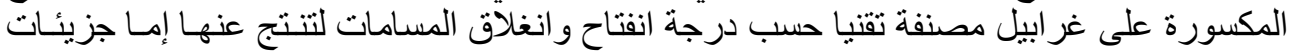

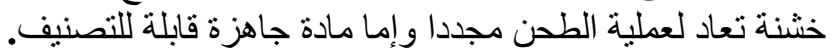

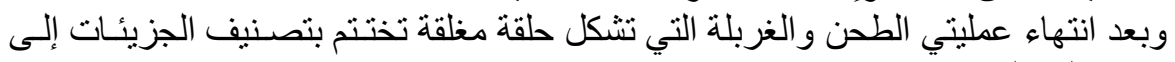
أنو اع المنتجات المختلفة. 


$$
\text { وفي هذه الحالة يتم أخذ عينة يتم فيها قياس: }
$$

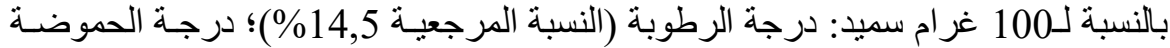

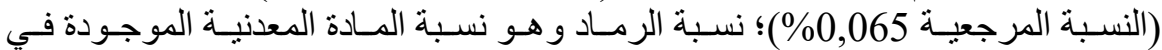
السميد؛حجم حبيبات السميد؛ قياس السميد الخشن (أعلى درجة)، الفرينة الناتجة عن السميد السيد

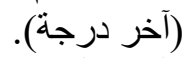

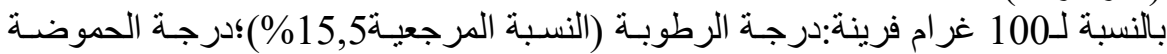

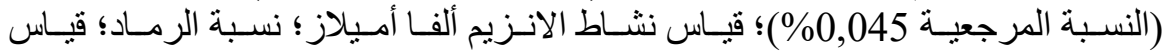
الغلوتين؛ خصائص الفرينة العادية.

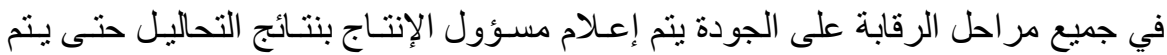
تصحيح الانحر افات إن وجدت النئ.

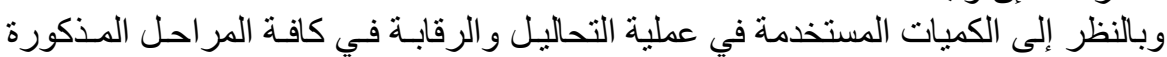

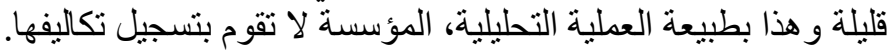

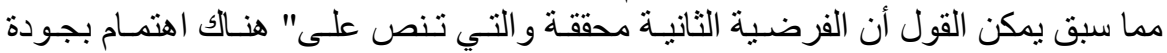

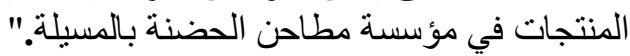
3.5. النتائج المتعلقة بمدى تأثير الآلات الإنتاجية على جودة منتجـات مؤسسـة مطاحن العضـنة بالمسيلة

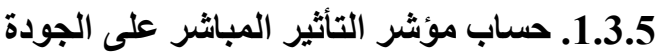

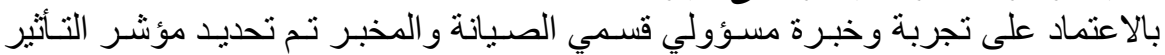

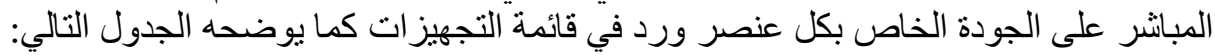

جدول رقم(01): مؤشر الثأثير المباثر على الجودة لتجهيزات المؤسسة

\begin{tabular}{|c|c|c|c|c|c|c|}
\hline 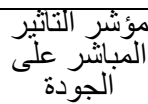 & الأمنشن & الصؤشَنَة & الجو ل مؤشر & اسم التجهيز أو الآلة & 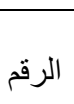 & 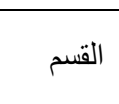 \\
\hline 1 & 1 & 1 & 1 & نافل افقي & 1 & \multirow{5}{*}{ الاستقبال } \\
\hline 2 & 2 & 1 & 1 & نافل عمودي & 2 & \\
\hline 3 & 3 & 1 & 1 & ميزان ذا السعة الكبيرة & 3 & \\
\hline 18 & 2 & 3 & 3 & غربال الة فصل بين القمح و الثُو أثب & 4 & \\
\hline 6 & 1 & 3 & 2 & خلايا تخزين القمح & 5 & \\
\hline 1 & 1 & 1 & 1 & نافل افقي & 6 & \multirow{11}{*}{ التنظيف } \\
\hline 2 & 2 & 1 & 1 & نافل عمودي & 7 & \\
\hline 3 & 3 & 1 & 1 & ميز ان ذا السعة المتوسط & 8 & \\
\hline 18 & 2 & 3 & 3 & غربال الة فصل & 9 & \\
\hline 27 & 3 & 3 & 3 & غربال ناز ع حصى وساحب غبار & 10 & \\
\hline 12 & 2 & 3 & 2 & مصنف القمح & 11 & \\
\hline 12 & 2 & 3 & 2 & اللة المعالج & 12 & \\
\hline 12 & 2 & 3 & 2 & المشط & 13 & \\
\hline 27 & 3 & 3 & 3 & غربال ساحب الغبار & 14 & \\
\hline 24 & 3 & 2 & 4 & اللة غسل القمح & 15 & \\
\hline 48 & 4 & 3 & 4 & خلابيار راحة & 16 & \\
\hline 1 & 1 & 1 & 1 & ناقل افقي & 17 & \multirow{5}{*}{ الالفرينة } \\
\hline 2 & 2 & 1 & 1 & نافل عمودي & 18 & \\
\hline 3 & 3 & 1 & 1 & ميزان & 19 & \\
\hline 36 & 3 & 3 & 4 & الات الدر افيل & 20 & \\
\hline 3 & 3 & 1 & 1 & فاصل الفرينة & 21 & \\
\hline
\end{tabular}




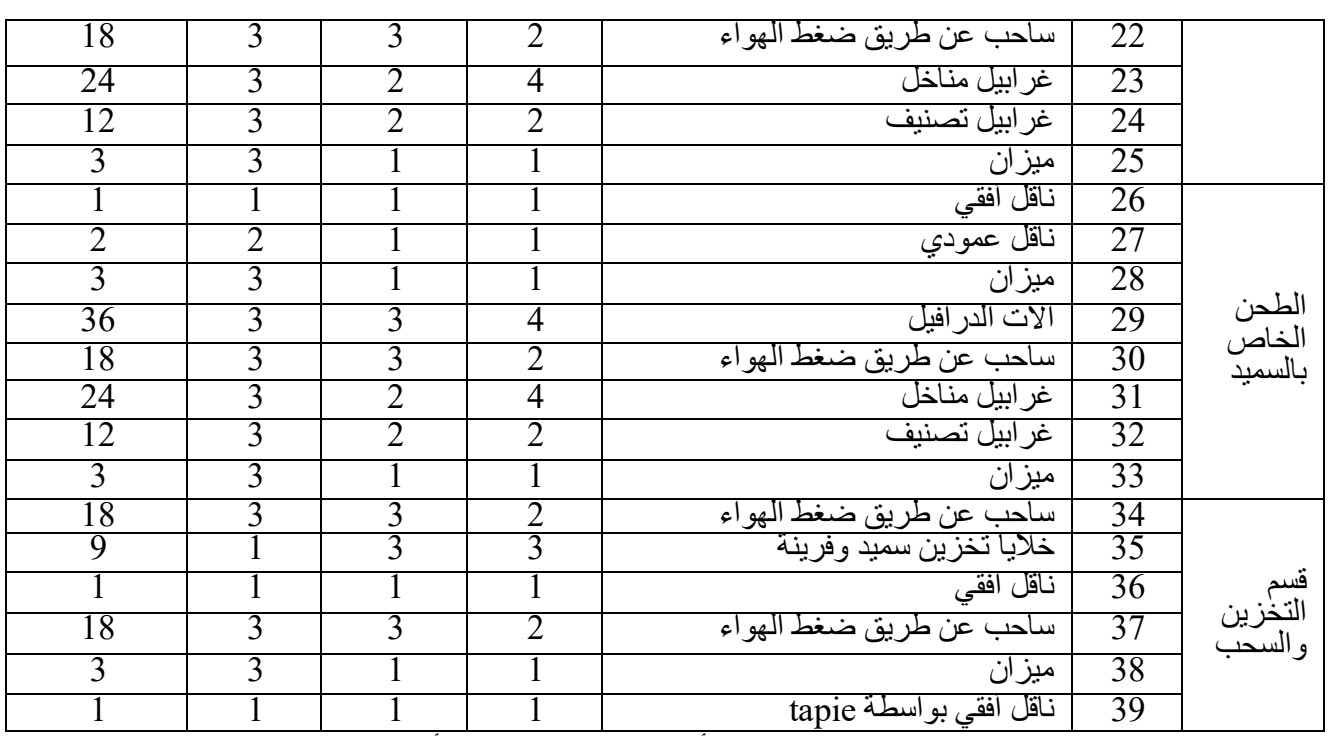

المصدر: من إعداد الباحثة إعتمادا على الأجوبة الخاصة بمؤشر التأثير المباثر على الجودة

\subsection{5 تحديد التجهيزات المؤثرة مباثرة على الجودة وترتيبها}

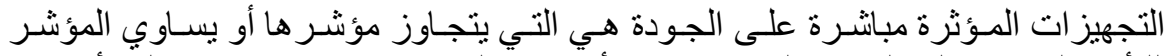

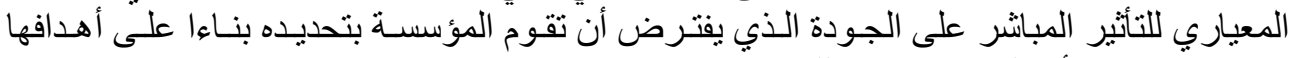

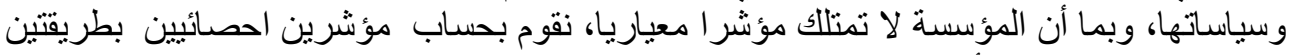

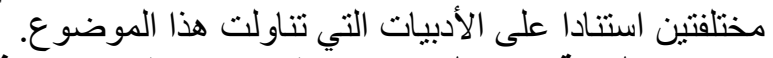

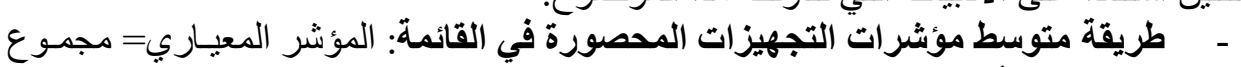

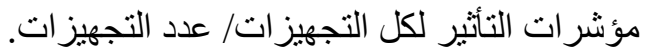
$39 / 467=$

$11,97=$

$12=$

حسب هذا المؤشـر فـإن التجهيزات المؤثرة مباشـرة على الجـودة هـي تلك التـي بيساوي

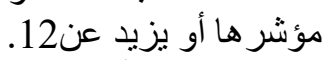

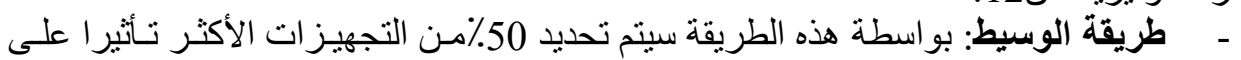

و هذا يعني أن 50٪ من التجهيزات الأكثر تأثير ا على الجودة هي تللك التي يساوي مؤشر ها

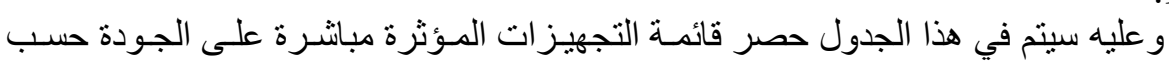
أو يفوق9 الطريقتين السابقتين لحسياب المؤشر المعياري. 
مساهمة صيانة الآلات في تحقيق جودة منتجات المؤسسة الاقتصادية:

در اسة حالة مؤسسة مطاحن الحضنة فئنة بالمسيلة

سمية ديقش

جدول رقم(02): قائمة التجهيزات المؤثرة مباشرة على الجودة

\begin{tabular}{|c|c|c|c|c|}
\hline \multicolumn{2}{|r|}{ طريقة الوسيط= } & \multicolumn{2}{|r|}{ طريقة المتوسط= 12} & \multirow{2}{*}{ 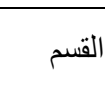 } \\
\hline 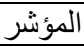 & اسم التجهيز & 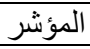 & اسم التجهيز & \\
\hline 18 & غربال آلة فصل بين القمح و الثو ائب & 18 & غربال آلة فصل بين القمح والثوائب & الاستقبال \\
\hline 18 & غربال آلة فصل & 18 & غربال آلة فصل & \\
\hline 27 & غربال ناز ع حصى وساحب غبار & 27 & غربال ناز ع حصى وساحب غبار & \\
\hline 12 & مصنف القمح & 12 & مصنف القمح & \\
\hline 12 & آلة المعالج & 12 & آلة المعالج & \\
\hline 12 & المشط & 12 & المشط & النتظيف \\
\hline 27 & غربال ساحب الغبار & 27 & غربال ساحب الغبار & \\
\hline 24 & آلة غسل القمح & 24 & آلة غسل القمح & \\
\hline 48 & خلايا الر احة & 48 & خلايا الراحة & \\
\hline 36 & & 36 & & \\
\hline 18 & آلات الدر افيل(1) ـ ـ. ـ. & 18 & & 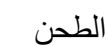 \\
\hline 24 & ساحب عن طريق ضغط الهو اء(1) & 24 & ساحب عن طريق ضغط الهو اء(1) & 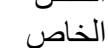 \\
\hline 12 & غر ابيل تصناخل (1) & 12 & غر ابيل تصنيف (1) غناخل (1) & بالفرينة \\
\hline 36 & & 36 & & \\
\hline 18 & آلات الدر افيل(2) & 18 & آلات الدر افيل(2) & \\
\hline 24 & ساحب عن طريق ضغط الهو اء(2) & 24 & ساحب عن طريق ضغط الهو اء(2) & الخاص الص \\
\hline 12 & غر ابيل مناخل (2) & 12 & غر ابيل مناخل (2) & بالسميد \\
\hline 18 & ساحب عن طريق ضغط الهو اء(3) & 18 & & قسم \\
\hline 9 & خلايا تخزين سميد وفرينة & 18 & ساحسب عن طن طريق ضنط الهو اءو(4) & 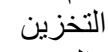 \\
\hline 18 & ساحب عن طريق ضغط الهو اء(4) & & ساحب ع صريى صعط الهو اء(4) & و السحب \\
\hline
\end{tabular}

المصدر: من إعداد الباحثة إعتمادا على الجدول رقم(01).

اعتمادا على قيمة المؤشر الخاص بكل تجهيز و على المؤشر المعيـاري بطريقتي المتوسـ

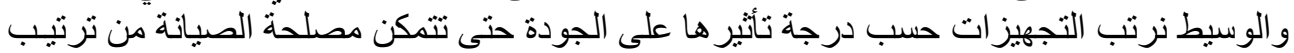

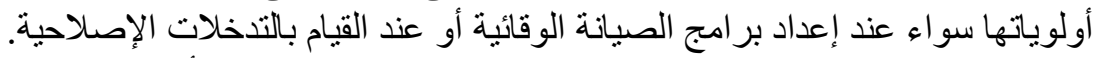

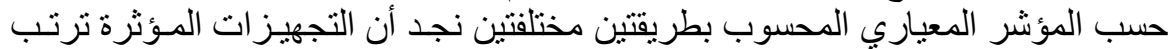

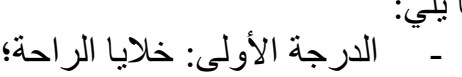

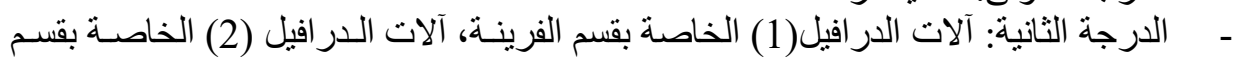
السمبد؛ - - الدرجة الثالثة: غربال ناز ع حصى وساحب غبار ، غربال ساحب غبار ؛

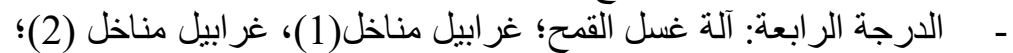

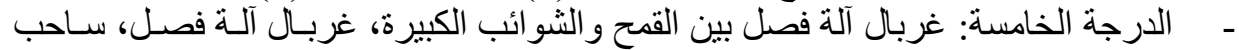

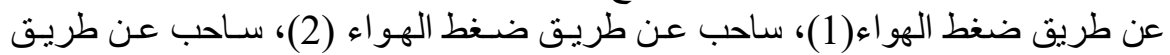

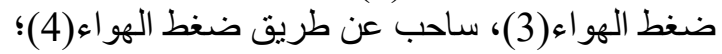

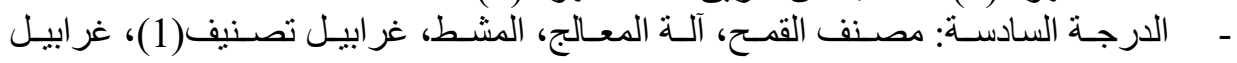
تصنيف (2)؛ (2) 
ـ - الدرجة السـابعة: خلايـا تخزين السميد و الفرينـة، هذه الأخيرة حسب المؤشـر المعيـاري

بالوسبط فقط.

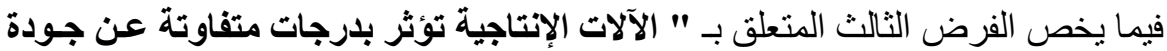

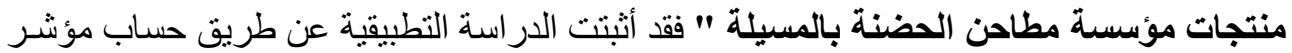

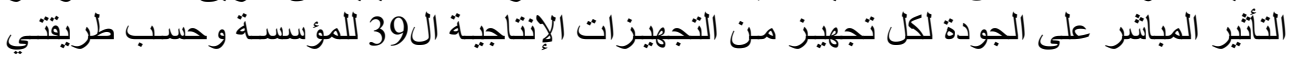

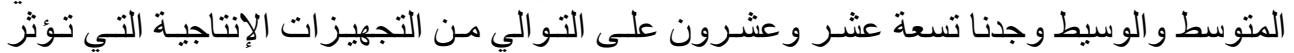

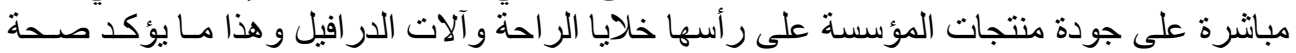

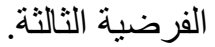

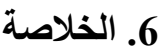

تمحور موضوع البحث حول الأثر الذي تحدثه وظيفة الصيانة على الصى جودة المنتجـات في مؤسسة مطاحن الحضنة بالمسيلة، وتم التوصل الأن إلى النتائج التالية:

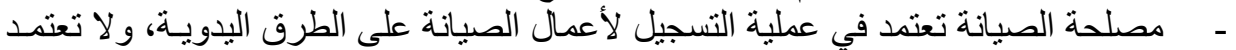

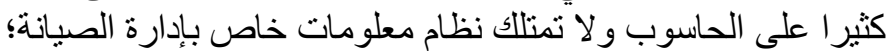
المصـلحة لا تسـتغل التسـيلات و التوثيقـات لأعمـال الصـيانة في معرفـة أسـباب تكرار الأعطال؛ الاعل

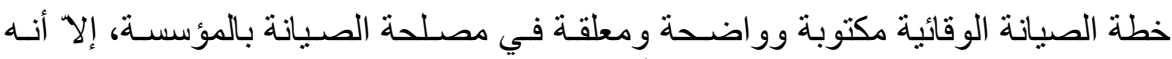

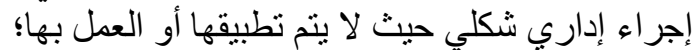

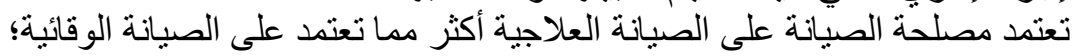

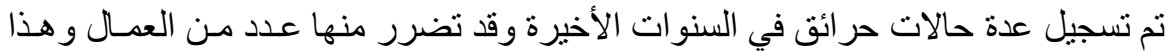

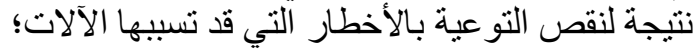

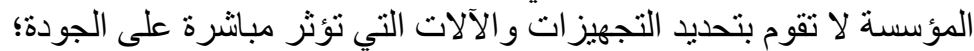
ارتفاع تكاليف الصيانة وخاصة العلاجية؛ خصصت المؤسسة ميز انية ضخمة مـن أجلـ إعـادة تجهيز المطحنـة ومصلحتي الصيانة

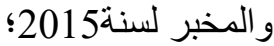
يساهم عمال الإنتاج في كثنف عيوب وأخطـاء العمليـات الإنتاجيـة وهو مـا يسـل عمليـة تداركها قبل تفاقمها؛

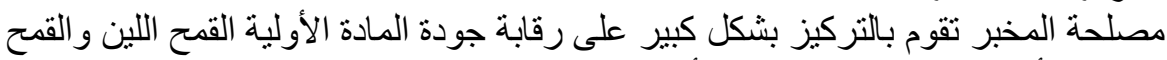

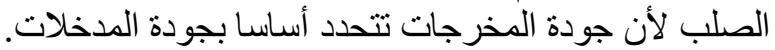

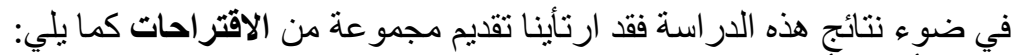

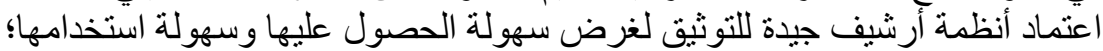

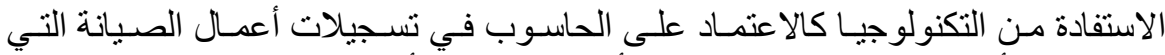

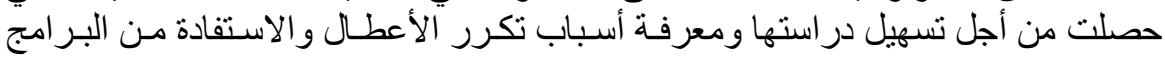

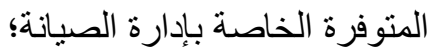

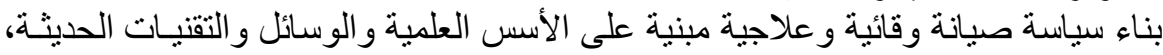

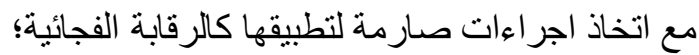

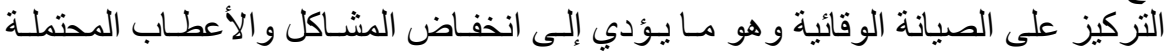

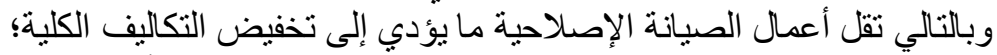

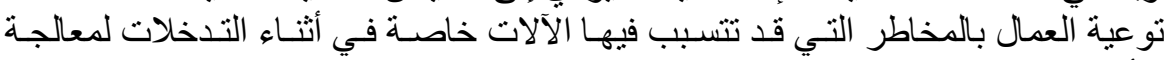

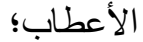


الاستفادة من قائمة التجهيز ات الـ 19و 20 التي تم إيجادها بطريقتي المتوسط و الوسيط على ودئ

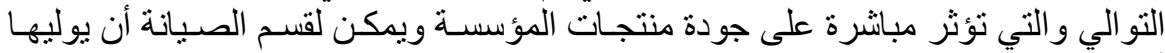

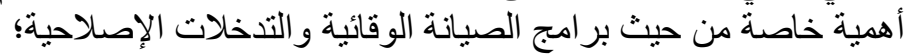

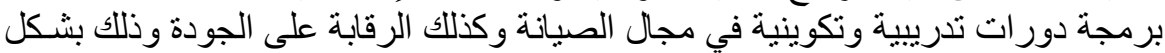
دوري لتعلم التقنيات الجديدة بحيث يكون التدريب فعال يؤدي إلى تحقيق الأهداف المرجوة الكية منه؛

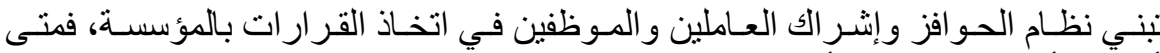

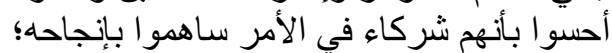

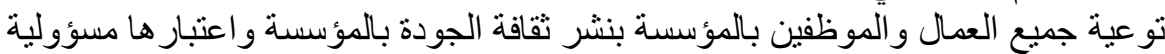

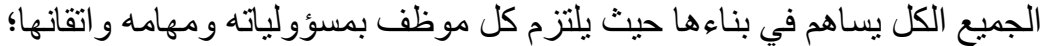
عقد ندوات وحضور ملتقيات تحسيسية وتظاهر ات تحث على ضرورة ولى وأهميـة تبنـي إدارة

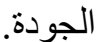

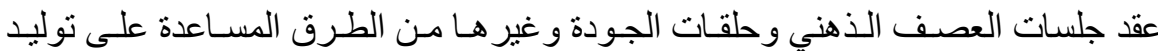

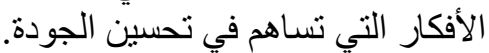

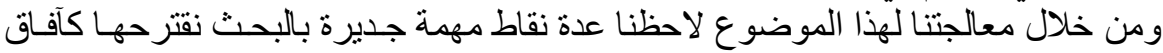

مدى نأثير أنماط الصيانة على فلسفة الإنتاج الآني؛

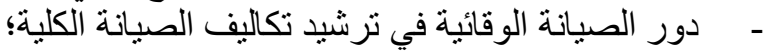

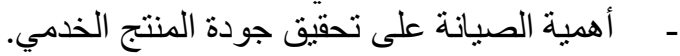

أحمد سبد مصطفى. (1998). إدارة الجودة الثاملةو الـ إيزو 9000. مطابع الدار الهندسية.

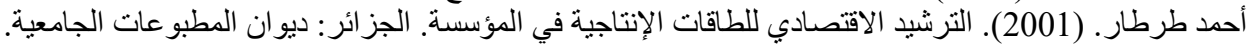

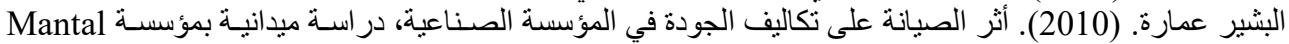

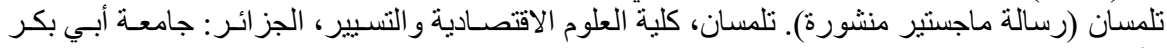
بالقايد. خضير كاظم حمود. (2007). إدارة الجودة وخدمة العملاء (الإصدار 01). عمان، الأردن: دار المسيرة للنشر و التوزيع و الطباعة. خضير كاظم حمود، و هايل يعقوب فاخوري. (2009). إدارة الإنتاج و العمليات (الإصـدار 01). عمـان: دار صـفاء للنشر و التوزيع. زكريا طاحون. (2010). إدارة الإنتاج و العمليات بالجودة الثاملة. مصر : دار النورة النوس للطباعة.

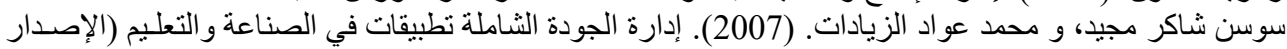

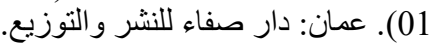

سونيا محمد البكري. (2001). إدارة الإنتاج و العمليات: مدخل النظم. الإنمان الإسكندرية: الدار الجامعية .

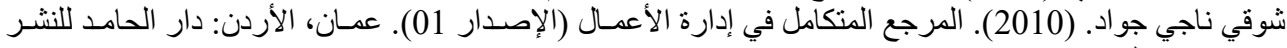
و التوزيع.

عادل حسن. (1998). مشاكل الإنتاج الصناعي. بيروت: دار دار النهضة العزبة العربية.

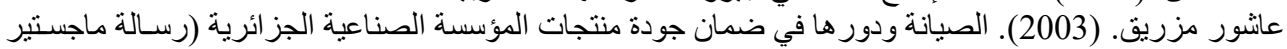

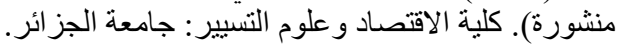

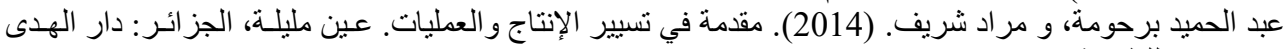
للطباعة. عبد الغاني تغلابت. (2006). تأثير الصيانة على تكاليف اللاجودة في المؤسسة الصناعية، در اسة حالة ملبنة الأور اس -

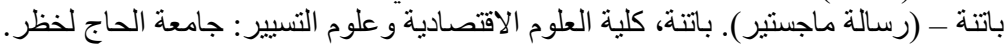
عبد الغفور يونس. (1997). التنظيم الصناعي و إدارة الإنتاج. الإسكندرية: المكتة المكتب العربي الحديث. 
|المجلد 02 العدد 03 (2020) ص 24-45

مجلـة بحوث الإدارة و الاقتصاد

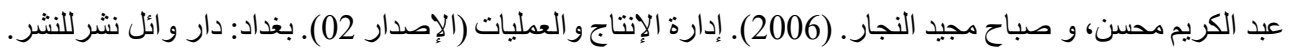

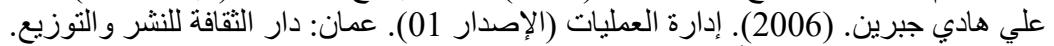

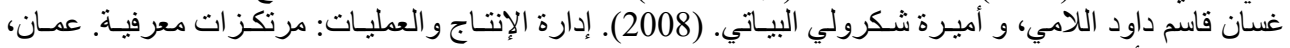

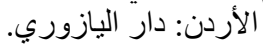

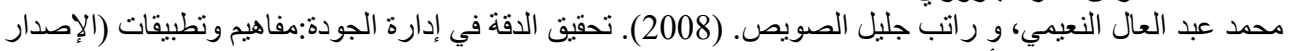

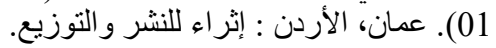

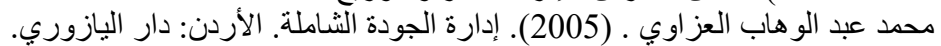

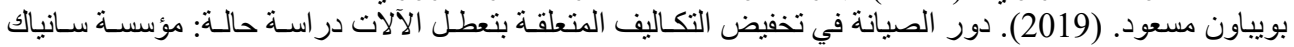

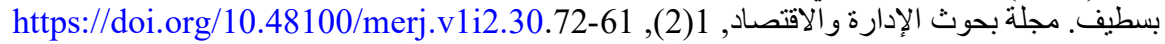

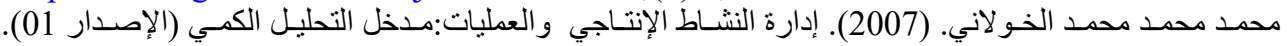
الاسكندرية: دار الوفياء.

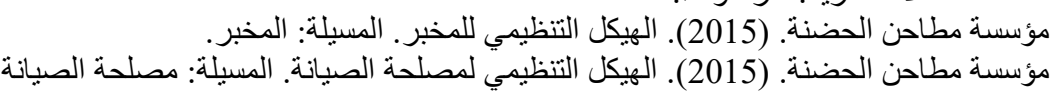

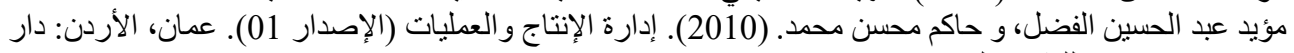

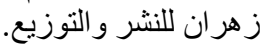

نبيل محمد مرسي. (2002). استر اتيجية الإنتاج و العمليات: مدخل استر اتيجي (الإصدار 01). الإسكندرية: دار الجامعة

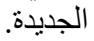

نجوى ر اشدي ـ (2009). جودة المنتوج كأداة لتحسين صورة العلامة، در اسة حالة علامة الالكترونيك لمؤسسة عنتر

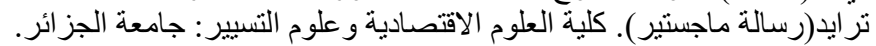

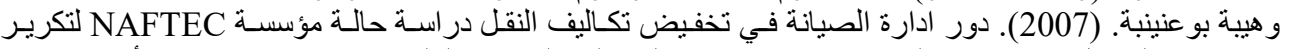

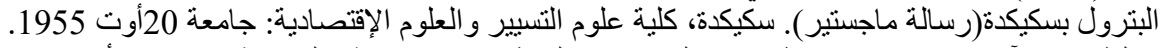

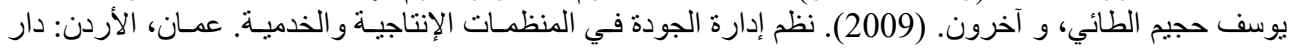
اليازوري.

\section{References}

Ahmed, M. (1998). Total Quality Management and ISO 9000. Engineering House Press. [In Arabic]

Ahmed, T. (2001). Economic rationalization of productive capacities in the organization. Algeria: OPU. [In Arabic]

Al-Bashir, O. (2010). The Impact of Maintenance on Quality Costs in the Industrial Corporation, a field study at the Mantal Corporation in Tlemcen (Master thesis). Tlemcen, University of Tlemcen. [In Arabic]

Khudair, H. (2007). Quality Management and Customer Service ( $1^{\text {st }}$ edition). Amman, Jordan: Dar Al-Masira for Publishing, Distribution and Printing. [In Arabic]

Khudair H., \& Hayel Y. F. (2009). Production and Operations Management ( $1^{\text {st }}$ edition). Amman: Safaa House for Publishing and Distribution. [In Arabic]

Zakaria, T. (2010). Production and Operations Management by total quality. Egypt: Dar AlNawras for printing. [In Arabic]

Sawsan, M., \& Al-Ziyadat M. A. (2007). Total Quality Management: Applications in Industry and Education ( $1^{\text {st }}$ edition). Amman: Safaa House for Publishing and Distribution. [In Arabic]

Al-Bakri, S. (2001). Production and Operations Management: A Systemic approach. Alexandria: University House. [In Arabic]

Shawqi, J. (2010). The Integrated Reference in Business Administration ( $1^{\text {st }}$ edition). Amman, Jordan: Al-Hamid House for Publishing and Distribution. [In Arabic]

Adel, H. (1998). Problems of industrial production. Beirut: Arab Renaissance House. 
Ashour, M. (2003). Maintenance and its role in ensuring the quality of the Algerian Industrial Corporation products (Master thesis). University of Algiers. [In Arabic]

Barahouma, A., \& Murad S. (2014). Introduction to production and operations management. Ain Melilla, Algeria: Dar El Hoda for Printing. [In Arabic]

Abdul-Ghani, T. (2006). The Impact of Maintenance on the Costs of no quality in the industrial organization, a case study of Ouras Dairy -Batna- (Master Thesis), Haj Lakhhdhar University. [In Arabic]

Abdul Ghafoor, Y. (1997). Industrial organization and production management. Alexandria: The Modern Arab Office. [In Arabic]

Abdul Karim, M., \& Al-Najjar, S. M. (2006). Production and Operations Management (2 ${ }^{\text {nd }}$ edition). Baghdad: Wael Publishing House. [In Arabic]

Ali Hadi Jibreen. (2006). Operations Management ( $1^{\text {st }}$ edition). Amman: House of Culture for Publishing and Distribution. [In Arabic]

Al-Lami, G. Q. D., \& Al-Bayati A. S. (2008). Production and Operations Management: Knowledge Pillars. Amman, Jordan: Dar Al-Yazuri. [In Arabic]

Al-Nuaimi, M., \& Al-Sweis R. J. (2008). Achieving Accuracy in Quality Management: Concepts and Applications ( $1^{\text {st }}$ edition). Amman, Jordan: Ithraa for Publishing and Distribution. [In Arabic]

Al-Azzawi, M. (2005). Total Quality Management. Jordan: Dar Al-Yazouri. [In Arabic]

Bouiban, M. (2019). The Role Of Maintenance In Reducing Costs Related To Machine Failure, Case Study: Saniak Company Setif. Management \& Economics Research Journal, 1(2), 61-72. https://doi.org/10.48100/merj.v1i2.30 [In Arabic]

Al-Khawlani, M. (2007). Managing Production Activity and Operations: An Introduction to Quantitative Analysis ( ${ }^{\text {st }}$ edition). Alexandria: Dar Al-Wafa. [In Arabic]

Al-Fadl, M. \& Hakem, M. (2010). Production and Operations Management ( $1^{\text {st }}$ edition). Amman, Jordan: Zahran House for Publishing and Distribution. [In Arabic]

Morsi, N. M. (2002). Production and Operations Strategy: A Strategic Approach (1 ${ }^{\text {st }}$ edition). Alexandria: The New University House. [In Arabic]

Rashdy, N. (2009). Product quality as a tool to improve the image of the mark. Case study of electronic mark Antar Trade Corporation (Master Thesis). University of Algiers. [In Arabic]

Bouanainba, W. (2007). The Role of the Maintenance Department in Reducing Transportation Costs: A Case Study of the NAFTEC Petroleum Refining Corporation in Skikda (Master Thesis). University of August 20, 1955. [In Arabic]

Al-Tai, Y.H. et all. (2009). Quality management systems in production and service organizations. Amman, Jordan: Dar Al-Yazuri. [In Arabic] 


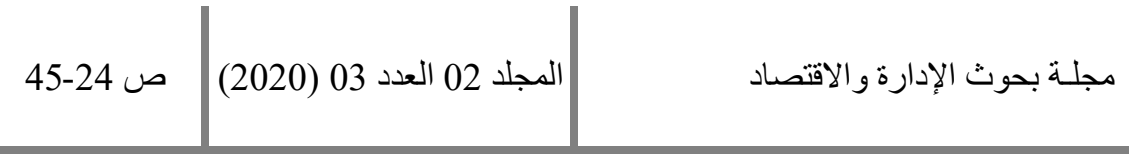

\title{
The Impact of Machinery Maintenance on Achieving Quality of Products of the Algerian Economic Institution: A Case of Al-Hodna Mills Company Semia Dekkache •
}

\footnotetext{
Received: 22-03-2020

Accepted: $07-05-2020$

Published: 21-06-2020

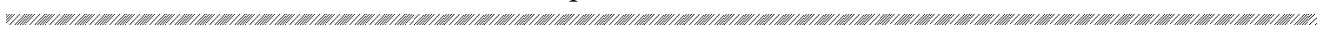

\begin{abstract}
:
This study aimed to know the impact of machinery maintenance on achieving the quality of products in the economic establishment by applying this in Al-Hodna mills institution in M'sila. By developing interview questions and directing them to the officials of maintenance and laboratory departments, documents were also used from various institutions' departments. The study reached several important results. There are practices for preventive maintenance and curative maintenance in the institution under study, an interest in the quality of products in the institution under study, and the identification of nineteen and twenty machines in two different ways that have a direct impact on the quality of products in the institution under study.
\end{abstract}

Keywords: Maintenance, Machinery, Product Quality, Al-Hodna Mills Company.

JEL Classification: L22, M11, L15.

(C) 2020 the Author(s). This is an open access article distributed under the terms of Creative Commons Attribution-Non Commercial License (CC BY-NC 4.0) which permits use, distribution and reproduction in any medium, provided the original work is properly cited and is not used for commercial purposes.

How to Cite: Dekkache, S. (2020). The Impact of Machinery Maintenance on Achieving Quality of Products of the Algerian Economic Institution: A Case of Al-Hodna Mills Company. Management \& Economics Research Journal, 2(3), 24-45. https://doi.org/10.48100/merj.v2i3.108 [In Arabic]

- Corresponding author: Farhat Abbas Setif 1 University (Algeria).

[ $\triangle$ dikachesemia@gmail.com] 